\title{
Presynaptic Release-Regulating Alpha2 Autoreceptors: Potential Molecular Target for Ellagic Acid Nutraceutical Properties
}

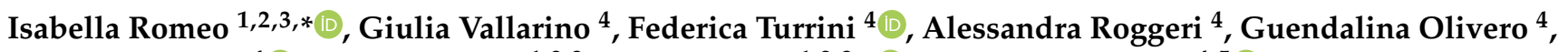 \\ Raffaella Boggia ${ }^{4}\left(\mathbb{D}\right.$, Stefano Alcaro ${ }^{1,2,3}$, Giosuè Costa ${ }^{1,2,3, * \mathbb{D}}$ and Anna Pittaluga 4,5 (D) \\ 1 Net4Science Academic Spin-Off, Università degli Studi “Magna Græcia" di Catanzaro, Campus "S. Venuta", \\ Viale Europa, 88100 Catanzaro, Italy; alcaro@unicz.it \\ 2 Dipartimento di Scienze della Salute, Università degli Studi “Magna Græcia” di Catanzaro, Campus "S. Venuta”, \\ Viale Europa, 88100 Catanzaro, Italy \\ 3 Associazione CRISEA-Centro di Ricerca e Servizi Avanzati per l'Innovazione Rurale, Località Condoleo, \\ 88055 Belcastro, Italy \\ 4 Department of Pharmacy, University of Genoa, Viale Cembrano, 4, 16148 Genoa, Italy; \\ giulia.vallarino94@gmail.com (G.V.); turrini@difar.unige.it (F.T.); roggeri@difar.unige.it (A.R.); \\ olivero@difar.unige.it (G.O.); boggia@difar.unige.it (R.B.); pittalug@difar.unige.it (A.P.) \\ 5 IRCCS Ospedale Policlinico San Martino, 16145 Genova, Italy \\ * Correspondence: isabella.romeo@unicz.it (I.R.); gcosta@unicz.it (G.C.)
}

\section{check for}

updates

Citation: Romeo, I.; Vallarino, G.; Turrini, F.; Roggeri, A.; Olivero, G.; Boggia, R.; Alcaro, S.; Costa, G.; Pittaluga, A. Presynaptic ReleaseRegulating Alpha2 Autoreceptors: Potential Molecular Target for Ellagic Acid Nutraceutical Properties. Antioxidants 2021, 10, 1759. https:// doi.org/10.3390/antiox10111759

Academic Editor: Alessandra Napolitano

Received: 9 October 2021

Accepted: 2 November 2021

Published: 4 November 2021

Publisher's Note: MDPI stays neutral with regard to jurisdictional claims in published maps and institutional affiliations.

Copyright: (c) 2021 by the authors. Licensee MDPI, Basel, Switzerland. This article is an open access article distributed under the terms and conditions of the Creative Commons Attribution (CC BY) license (https:// creativecommons.org/licenses/by/ $4.0 /)$.

\begin{abstract}
Polyphenol ellagic acid (EA) possesses antioxidant, anti-inflammatory, anti-carcinogenic, anti-diabetic and cardio protection activities, making it an interesting multi-targeting profile. EA also controls the central nervous system (CNS), since it was proven to reduce the immobility time of mice in both the forced swimming and the tail-suspension tests, with an efficiency comparable to that of classic antidepressants. Interestingly, the anti-depressant-like effect was almost nulled by the concomitant administration of selective antagonists of the noradrenergic receptors, suggesting the involvement of these cellular targets in the central effects elicited by EA and its derivatives. By in silico and in vitro studies, we discuss how EA engages with human $\alpha_{2 \mathrm{~A}}$-ARs and $\alpha_{2 \mathrm{C}}$-AR catalytic pockets, comparing EA behaviour with that of known agonists and antagonists. Structurally, the hydrophobic residues surrounding the $\alpha_{2 \mathrm{~A}}$-AR pocket confer specificity on the intermolecular interactions and hence lead to favourable binding of EA in the $\alpha_{2 \mathrm{~A}}-\mathrm{AR}$, with respect to $\alpha_{2 \mathrm{C}}-\mathrm{AR}$. Moreover, EA seems to better accommodate within $\alpha_{2 \mathrm{~A}}$-ARs into the TM5 area, close to S200 and S204, which play a crucial role for activation of aminergic GPCRs such as the $\alpha_{2}$-AR, highlighting its promising role as a partial agonist. Consistently, EA mimics clonidine in inhibiting noradrenaline exocytosis from hippocampal nerve endings in a yohimbine-sensitive fashion that confirms the engagement of naïve $\alpha_{2}$-ARs in the EA-mediated effect.
\end{abstract}

Keywords: pomegranate tannins; ellagic acid; molecular modelling; $\alpha_{2}$-adrenoreceptors; $\alpha_{2}$-ARs; molecular dynamic simulations; antioxidant; natural compounds; antidepressant activity; food chemistry

\section{Introduction}

Pomegranate (Punica granatum L.) is a very ancient edible fruit originating in the Middle East and North Africa, used from the dawn of history as a healing and healthpromoting fruit in traditional medicine [1]. In the past decades, this rustic crop has obtained high popularity as a nutraceuticals source, becoming a high-value crop. Moreover, it has demonstrated increased importance due to its adaptability to different climatic conditions, its resilience and longevity, and its high drought and salinity resistance [2].

Today, pomegranate cultivation is widely spread in many tropical and subtropical regions, and about two million tons of fruits are produced annually worldwide [3]. Particularly, India, Iran, China, Turkey, the United States, Spain, South Africa, Peru, Chile, and Argentina represent the major producers and exporters of this fruit [4]. 
Pomegranate fruit is of great economic and nutritional interest, and it is in high demand due to its wide range of industrial uses, especially for direct consumption, for juice production, and oil extraction from its seeds [2]. The nutritional value of pomegranate is linked to its naturally high content of phenolic compounds with antioxidant properties [5]. Many studies, mainly in vitro, demonstrated the health benefits and the functional properties of this fruit in the prevention of several peripheral disorders such as cancer, cardiovascular diseases, chronic inflammatory diseases, and metabolic disorders (i.e., diabetes, obesity) [6]. Moreover, the beneficial effects of pomegranate phenolic compounds on central neuroinflammatory and neurodegenerative pathologies, including multiple sclerosis, Alzheimer's disease, Parkinson's diseases, epilepsy, and depression, have been highlighted too [7-9].

The main industrial product from pomegranate is its juice, obtained by aril squeezing, which represents the edible portion of the fruit, but recently there has been an increased focus on pomegranate by-products as a source of nutraceuticals. It has been determined that by-products, especially the peels, have higher levels of bioactive compounds and antioxidant activity than juice, opening new possibilities for pomegranate manufacturers to recover and exploit these by-products in a zero-waste economy perspective [10]. A major class of compounds in pomegranate fruit is the hydrolysable tannins, including ellagic acid, punicalagin, and gallic acid [11].

Ellagic acid (EA) is a chromene-dione derivative (3,7,8-tetrahydroxy-chromeno[5,4,3cde]chromene-5,10-dione), which is derived from the spontaneously lactonization of hexahydroxydyphenic acid (HHDP) [12]. In its free form, or as constituent of ellagitannins (ETs), or conjugates with different monosaccharides (EA-glycosides), EA is considered the main phenolic compound responsible for the numerous health properties of pomegranate [12]. ETs are esters of gallic acid (GA) and hexahydroxydiphenic acid (HHDP) units, connected with mainly $\beta$-D-glucose as sugar residue. Punicalagin (2,3-(S)hexahydroxydiphenoyl-4,6-(S,S)-gallagyl-D-glucose), a large molecule consisting of ellagic acid and gallagic acid linked via a glucose unit, is the most abundant ET in pomegranate and it is specific to the Punica genus [8]. Data from preclinical studies in the literature support the healthy properties of both EA and ETs. These include the ability to interfere with tumor cell proliferation, the cell cycle, invasion and angiogenesis by making it a multitarget candidate for various cancer treatments [13]. It also places a particular emphasis on the role of EA in central inflammatory and (auto)-immunological diseases, but also for depression, anxiety and aged-related neurological impairments [7,14-16] (Figure 1).

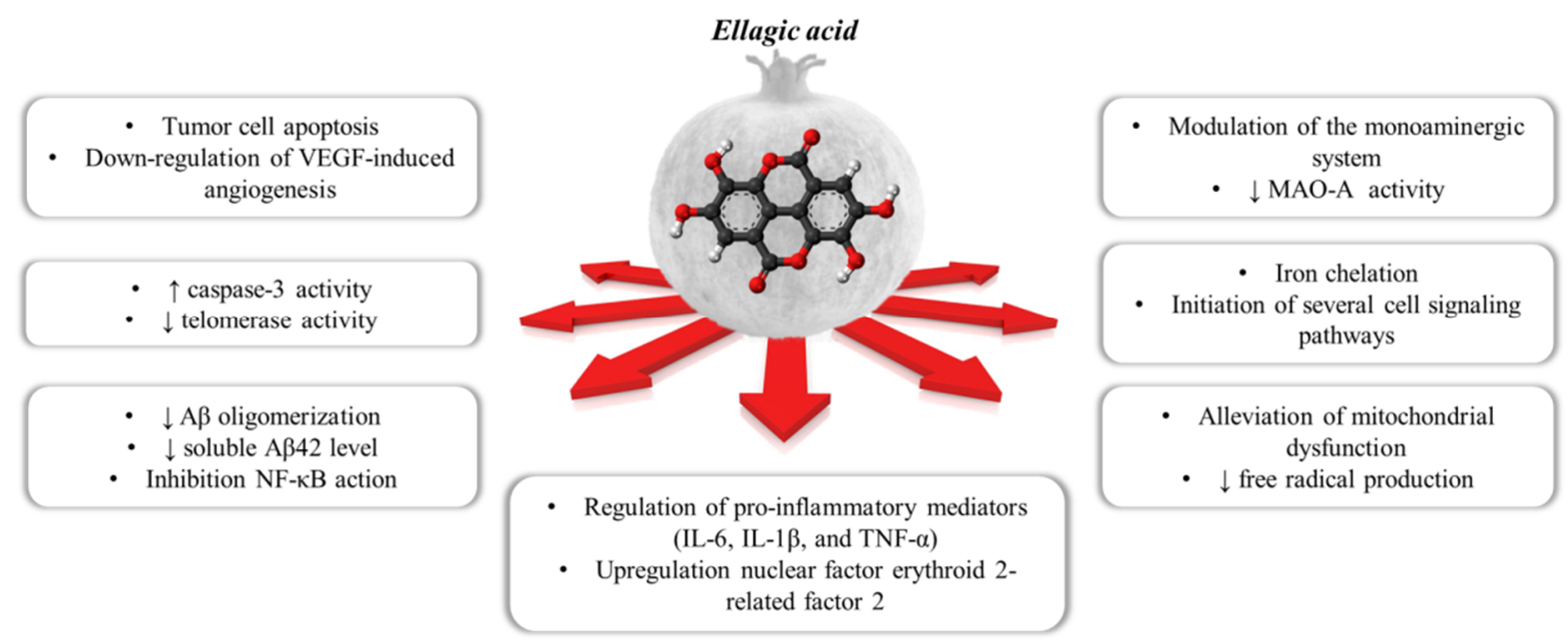

Figure 1. The polypharmacological effects regulated by ellagic acid contained within the pomegranate.

As far as the mood disorders are concerned, EA was proven to reduce the immobility time of mice in both the forced swimming and the tail-suspension tests, with an efficiency comparable to that of classic antidepressants [17]. Interestingly, the anti-depressant-like 
activity was almost nulled by the concomitant administration of selective antagonists of the noradrenergic receptors (namely the $\alpha_{1}$, the $\alpha_{2}$ and the $\beta$ receptors) and by modulators of the serotonergic systems as well (including receptor antagonists and synthesis inhibitors) $[17,18]$, suggesting the involvement of these cellular targets in the central effects elicited by EA and its derivatives.

Among the noradrenergic receptors, we focussed on the $\alpha_{2}$ receptors $\left(\alpha_{2}\right.$-ARs) that, in the central nervous system (CNS), act as presynaptic inhibitory autoreceptors in noradrenergic nerve endings/varicosities $[19,20]$. The $\alpha_{2}$-ARs are indirectly tuned by antidepressants acting as noradrenaline (NA) re-uptake inhibitors (NRI) [21]. By increasing NA bioavailability in the synaptic cleft, these drugs cause the continuous stimulation of the presynaptic $\alpha_{2}$-Ars, leading to their down regulation. A comparable outcome also can be triggered by the continuous direct activation of the presynaptic $\alpha_{2}$-ARs with agonists. In both cases, the final outcome is the silencing of the presynaptic mechanism of autocontrol of the release of the biogenic amine and, consequently, the reinforcement of the noradrenergic transmission [22-24]. Notably, the $\alpha_{2}$-ARs also exist in astrocytes, where they control the phenotype of the glial cells favouring the non-inflammatory one [25]; whether and how these receptors desensitize was so far scarcely investigated.

The $\alpha_{2}$-ARs are G protein coupled receptors (GPCRs) negatively associated to the adenylyl cyclase (AC) that reduce the gating of the voltage-operated calcium channels (VOCCs), concomitantly favouring the opening of the $\mathrm{K}^{+}$-channels, to inhibit cellular functions. There are three characterized $\alpha_{2}$-AR subtypes, the $\alpha_{2 A^{-}} \mathrm{AR}, \alpha_{2 B}-\mathrm{AR}$ and $\alpha_{2 C^{-}}$ AR [26], which are well conserved across mammals and are differently distributed in postganglionic sympathetic neurons and CNS noradrenergic neurons.

The $\alpha_{2 \mathrm{~A}}$-ARs and the $\alpha_{2 \mathrm{C}}$-ARs are mainly expressed in noradrenergic neuronal projections from the Locus coeruleus to other central regions, with higher expression on the varicosities in dendritic and axonal processes, as well as in nerve terminals [20]. The $\alpha_{2 \mathrm{~A}}$-ARs and the $\alpha_{2 \mathrm{C}}$-ARs are also present peripherally, on postganglionic sympathetic neurons, where again they act as inhibitory autoreceptors. Differently, the $\alpha_{2 B}$-ARs are preferentially expressed in the periphery, their presence in the CNS still representing a matter of debate [27].

We recently demonstrated that the systemic administration of an orally available formulation of EA efficiently recovers the NA exocytosis in the cortex of aged mice, restoring it to a level comparable to that observed in young animals $[8,9,28]$, and also reducing the endogenous levels of proinflammatory cytokines [28]. Taking into consideration that (i) the production of pro-inflammatory cytokines is tuned by NA [29-32], (ii) the efficiency of NA transmission is modulated by cytokines [22,33], and (iii) a common trait of the cytokinesNA cross-talk in the CNS is represented by the noradrenergic $\alpha_{2}$-ARs, we hypothesized that these receptors could be involved in the beneficial effects exerted by EA in aged mice.

To test our hypothesis, we focused on the $\alpha_{2 \mathrm{~A}}$-ARs and the $\alpha_{2 \mathrm{C}}$-ARs, because of their preferential central distribution that would support their involvement in the control of mood disorders and in the anti-depressant activity. We carried out in-silico studies to explore the binding modes of EA into human $\alpha_{2 \mathrm{~A}}$-ARs and $\alpha_{2 \mathrm{C}}$-AR catalytic pockets, comparing EA behaviour with those ones of a known agonist (clonidine) or antagonist (yohimbine), respectively. Through molecular docking and molecular dynamic simulations (MDs), we investigated whether the absence of the positively charged center in the EA could affect the binding to the $\alpha_{2 A}$-ARs structures. Then, we applied a functional in vitro experimental approach to evaluate whether and how EA interacts with naïve $\alpha_{2}$-ARs.

\section{Materials and Methods}

\subsection{Computational Protocols}

All computational studies were carried out by means of Schrödinger Suite 2018-1 [34]. The x-ray crystallographic structures of the $\alpha_{2 \mathrm{~A}}-\mathrm{AR}$ in complex with a partial agonist (PDB code: 6KUY) [26,35], and with the antagonist (PDB code: 6KUX) [36], and the $\alpha_{2 \mathrm{C}}-\mathrm{AR}$ in complex with an antagonist (PDB code: $6 \mathrm{KUW}$ ) [37] were used. $\alpha_{2 \mathrm{~A}}-\mathrm{AR}$ and $\alpha_{2 \mathrm{C}}-\mathrm{AR}$ 
structures were prepared by using the Maestro Protein Preparation Wizard [38] tool. All the hydrogen atoms were added, and the bond orders and the formal charges were adjusted for the hetero groups. The protonation states for all amino acids at physiological $\mathrm{pH}$ were calculated according to the Epik tool [39], and in particular, all aspartate residues were deprotonated in the inactive state of GPCRs, except for D113 which was protonated in the intermediate state. Missing residue atoms and loops were filled. Water molecules farther than $5 \AA$ from heteroatoms were deleted. The structures were refined to optimize hydrogenbonds and energy minimized by using OPLS_2005 as a force field at pH 7.4 [40,41]. For the ligands preparation, three-dimensional (3D) coordinates were generated for the ellagic acid, the partial agonist, and the antagonist such as clonidine and yohimbine, respectively, with LigPrep [42]. Then, target binding sites were defined by means of a regular grid box of about 27,000 $\AA^{3}$ centred on the co-crystallized ligands for each structure. All docking simulations were computed using the Glide [43] ligand flexible algorithm, at the standardprecision (SP) level. The best docked poses of ellagic acid, yohimbine and clonidine in complex to $\alpha_{2 \mathrm{~A}}$-AR and $\alpha_{2 \mathrm{C}}-\mathrm{AR}$ structures were submitted to $50 \mathrm{~ns}$ of molecular dynamics simulations (MDs) by using Desmond ver. 4.2 [44]. The POPC membrane was set up on the retrieved membrane coordinates by using the Orientation of Proteins in Membranes (OPM) database [45] for each PDB structure. The systems were solvated in the TIP3P explicit solvent model and counter ions were added to neutralize the system net charge. The Desmond membrane relaxation protocol was used to equilibrate each system [46]. After optimization of the solvated models, the default equilibration protocol of Desmond was used to relax the whole systems which included two energy minimizations of 2000 steps: in the first run, the systems were restrained with a force constant of $50 \mathrm{kcal} \mathrm{mol}^{-1} \mathrm{~A}^{-1}$, while in the second one, the whole systems were released without any restrains. The final MD production for the three complexes was carried out for a simulation time of $50 \mathrm{~ns}$. The following conditions for MDs were used: NPT ensemble, a temperature of $300 \mathrm{~K}$, a pressure of 1 bar, with the Berendsen thermostat-barostat, a recording interval equal to 250 ps both for energy and for trajectory collecting 1000 frames for each simulation. In order to examine the ligand stability in the respective accommodation into the ARs, the distance between the centroid of the ligand and D113, S200 and S204 residues for $\alpha_{2 A}-A R s$, and D131, S214 and S218 residues for $\alpha_{2 C}$-ARs, were calculated [47]. The subsequent free energy calculation for each complex was calculated. One thousand snapshots from $50 \mathrm{~ns}$ of MDs were applied for the MM/GBSA free energy calculations $[48,49]$ based on the following equation:

$$
\Delta \mathrm{G}_{\text {bind }}=\mathrm{G}_{\text {comp }}-\mathrm{G}_{\text {pro }}-\mathrm{G}_{\text {lig }}=\Delta \mathrm{E}_{\text {ele }}+\Delta \mathrm{E}_{\text {vdw }}+\Delta \mathrm{E}_{G B}+\Delta \mathrm{E}_{\text {surf }}
$$

where $\mathrm{G}_{\text {comp }}, \mathrm{G}_{\text {pro }}$ and $\mathrm{G}_{\text {lig }}$ denotes the free energy of the complex, protein and the ligand; by splitting the energy contribution, it referred to $\Delta \mathrm{E}_{\text {ele }}$ and $\Delta \mathrm{E}_{v d w}$ as the gas-phase interaction energy between protein and ligand, thus including the electrostatic energy term and van der Waals energy term, respectively. Meanwhile, $\Delta \mathrm{E}_{G B}$ and $\Delta \mathrm{E}_{\text {surf }}$ indicate the polar and nonpolar desolvation free energy, respectively. The implicit solvation was calculated using the GB model [50], while the non-polar solvation energy was calculated using the solvent accessible surface area algorithm.

$\Delta \mathrm{G}_{\text {bind }}$ reported in this study omitted the entropy contribution due to its relatively high computational demand and the lake of information of the conformational entropy that could lead to the introduction of additional error into the results [51].

\subsection{In Vitro Functional Pharmacological Studies: Animals}

Mice (male, strain C57BL/6J) were obtained from Charles River (Calco, Italy) and housed in the animal facility of the Department of Pharmacy (DIFAR), Pharmacology and Toxicology Section (Genoa, Italy), under controlled environmental conditions (ambient temperature $=22{ }^{\circ} \mathrm{C}$, humidity $=40 \%$ ) on a 12-h light $/$ dark cycle with freely available food and water. Mice were euthanized by cervical dislocation, followed by decapitation, and their hippocampi rapidly removed. 
Animal care and experimental procedures were in accordance with the ARRIVE guidelines and the European Communities Parliament and Council Directive of 22 September 2010 (2010/63/EU), and with the Italian D.L. n. 26/2014, and were approved by the Local Committee for Animal Care and Welfare of the University of Genova and the Italian Ministry of Health (DDL 26/2014 and previous legislation; protocol number $n^{\circ}$ 75F11.N.IMY). In line with the 3 Rs principles (reduction, refinement and replacement), all efforts were made to minimize the number of animals used and their suffering.

\subsection{Preparation of Synaptosomes}

Synaptosomes are pinched-off nerve terminals that contain structures (e.g., vesicles, mitochondria, endoplasmic reticulum, synthetic and enzymatic pathways, see Olivero et al., 2021 [52]) that are present in the neuronal processes they originate from, confirming their presynaptic origins. Synaptosomes can take up, synthesize, metabolize, store, and release transmitters, and possess naïve receptors and transporters, whose activation controls the synaptosomal functions, particularly transmitter exocytosis. Synaptosomes are obtained by homogenizing brain tissues, which are then isolated by density-gradient centrifugation as previously described [53]. Briefly, the tissue was homogenized in 10 volumes of $0.32 \mathrm{M}$ sucrose, buffered to $\mathrm{pH} 7.4$ with Tris-(hydroxymethyl)-amino methane (TRIS, final concentration $0.01 \mathrm{M}$ ) using a glass/Teflon tissue grinder (clearance $0.25 \mathrm{~mm}$ ). The homogenate was centrifuged at $1000 \times g$ for $5 \mathrm{~min}$ to remove nuclei and debris; the supernatant was gently layered on a discontinuous Percoll gradient $(6,10$, and $20 \% \mathrm{v} / \mathrm{v}$ in Tris-buffered $0.32 \mathrm{M}$ sucrose) and then centrifuged at $33,500 \times \mathrm{g}$ for $6 \mathrm{~min}$. The layer between 10 and $20 \%$ Percoll, which correspond to the synaptosomal fraction, was collected, and washed by centrifugation at $19,000 \times g$ for $15 \mathrm{~min}$. The synaptosomal pellet was then resuspended in a physiological medium of the following composition (mM): $\mathrm{NaCl}, 140$; $\mathrm{KCl}, 3 ; \mathrm{MgSO}_{4}, 1.2 ; \mathrm{CaCl}_{2}, 1.2 ; \mathrm{NaH}_{2} \mathrm{PO}_{4}, 1.2 ; \mathrm{NaHCO}_{3}, 5 ; \mathrm{HEPES}, 10$; glucose, 10; $\mathrm{pH} 7.4$.

\subsection{Release Experiments}

Hippocampal synaptosomes were incubated for $15 \mathrm{~min}$ at $37^{\circ} \mathrm{C}$ in a rotary water bath with the radioactive tracer $\left[{ }^{3} \mathrm{H}\right] \mathrm{NA}$ (f.c.: $30 \mathrm{nM}$ ), in the presence of $0.1 \mu \mathrm{M}$ 6-nitroquipazine to avoid the false labelling of serotonergic terminals. Identical aliquots of the synaptosomal suspension were then stratified as a thin monolayer on microporous filters at the bottom of parallel chambers maintained at $37^{\circ} \mathrm{C}$ of a Superfusion System (Ugo Basile, Comerio, Varese, Italy) [54,55], as first proposed by Raiteri and colleagues in 1974 (Figure 2) [54-56].

The superfusion apparatus consists of 20 units of superfusion, composed of an upper chamber (to heat the superfusion medium) and a lower chamber, where synaptosomes are stratified on a microporous filter as a monolayer (A). The superfusion medium is continuously collected by means of a peristaltic pump at a constant flow rate $(0.5 \mathrm{~mL} / \mathrm{L})$. This continuous up-down superfusion of the synaptosomal monolayer (B) assures the removal of any endogenous substances (C), therefore minimizing any retrograde effects (D). The presynaptic naïve receptors on the superfused synaptosomes are therefore "ligand-free", and their release-regulating activity can be triggered only by adding exogenous agonist(s) to the superfusion medium to activate the receptor-mediated signal (D). Differently, in this experimental paradigm, antagonists are "per se" inactive but became functionally active when added concomitantly to agonists, because of their ability to compete with agonists at presynaptic receptors modulating the transmitter exocytosis. The selective labelling with radioactive tracers (i.e., $\left[{ }^{3} \mathrm{H}\right] \mathrm{NA}$ ) of a specific subpopulation of terminals allows monitoring of the effects elicited by the receptors located on a selected subpopulation of nerve terminals (in our case the noradrenergic ones), impeding artefacts that may originate from the presence of the receptor under study on other subfamilies of terminals. The quantification of the radioactive tracer in the collected samples permits the correlation of the changes in transmitter exocytosis to the concentrations of the ligands in the superfusion medium and, therefore, to the activation of the presynaptic receptors controlling the efficiency of transmitter release (elicited in our case by a depolarizing stimulus, i.e., the $12 \mathrm{mM} \mathrm{KCl} \mathrm{C).}$ 


\section{The up-down superfusion of synaptosomes}

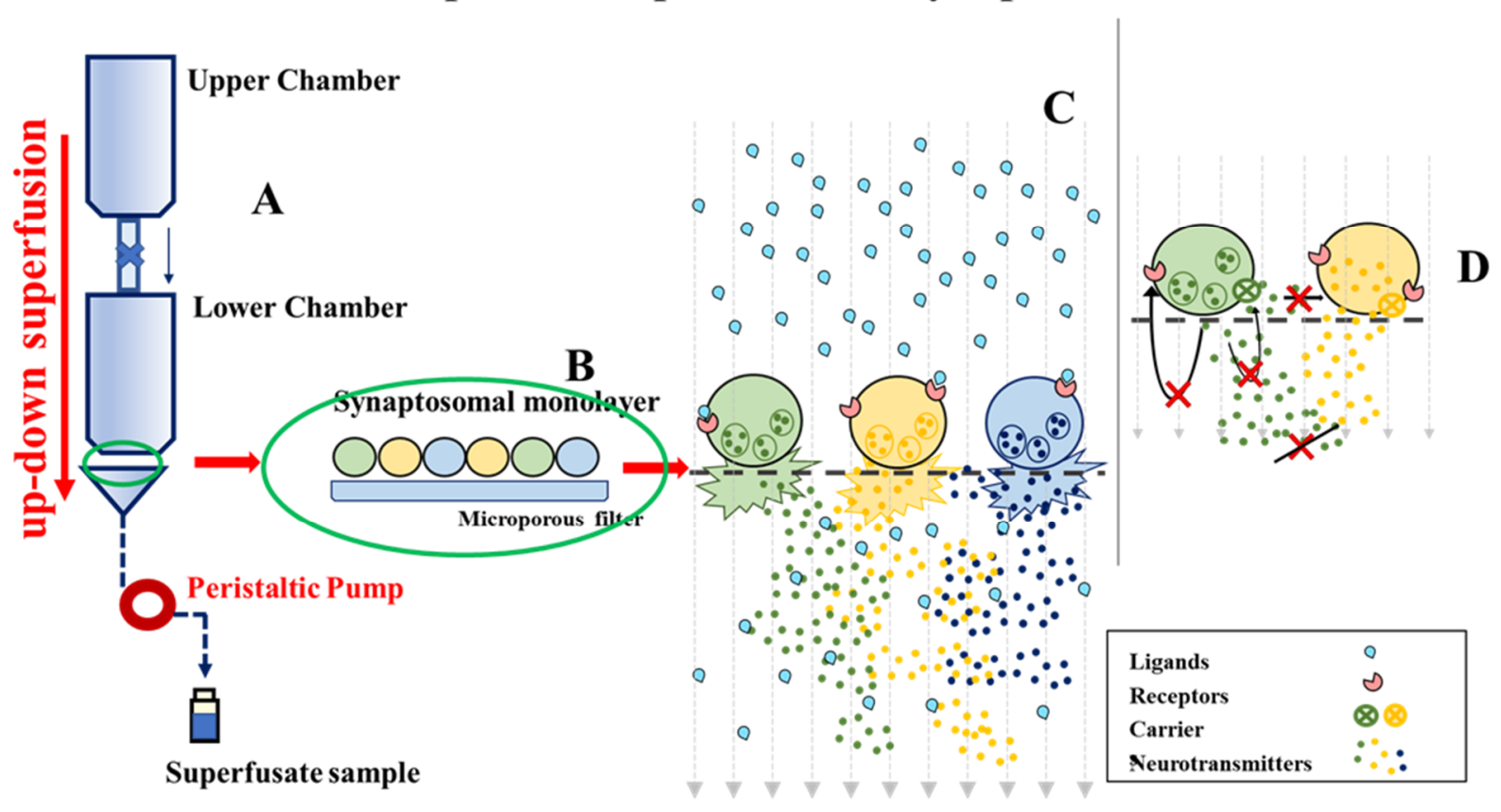

Figure 2. The superfusion apparatus (see text) [54,55].

Synaptosomes were continuously "up-down" superfused with an isosmotic-isotonic ionic solution at a constant flow rate $(0.5 \mathrm{~mL} / \mathrm{min})$ for $36 \mathrm{~min}$ to equilibrate the system. At $\mathrm{t}=39$, synaptosomes were transiently exposed $(90 \mathrm{~s})$ to a high $\mathrm{KCl}$-containing medium (12 mM, KCl, substituting for an equimolar concentration of $\mathrm{NaCl}$ ), in the absence or in the presence of clonidine and ellagic acid, alone or concomitantly added with yohimbine. Superfusate fractions were collected as follows: two 3-min fractions (basal release), one before $(\mathrm{t}=35-39 \mathrm{~min}, \mathrm{~b} 1)$ and one after $(\mathrm{t}=45-48 \mathrm{~min}, \mathrm{b3})$ a 6-min fraction $(\mathrm{t}=39-45 \mathrm{~min}$, evoked release, b2). The $12 \mathrm{mM} \mathrm{KCl-evoked}\left[{ }^{3} \mathrm{H}\right] \mathrm{NA}$ overflow was calculated by subtracting the neurotransmitter content in the $b 1$ and $b 3$ fractions from that in the $b 2$ fraction. The amount of radioactivity in each superfusate fraction was expressed as a percentage of the total synaptosomal radioactivity. Data are reported as the mean \pm SEM of independent determinations obtained in different experiments run in triplicate (at least three superfusion chambers for each experimental condition). The effects of EA, yohimbine and clonidine were expressed as a percentage of the $\mathrm{KCl}$-induced overflow in the absence of these ligands (percent of residual).

\subsection{Western Blot Analysis}

Mouse hippocampus was homogenated in RIPA lysis buffer (10 mM Tris, pH 7.4, $150 \mathrm{mM} \mathrm{NaCl}, 1 \mathrm{mM}$ EDTA, $0.1 \%$ SDS, $1 \%$ Triton X-100, $1 \mathrm{mM}$ sodium orthovanadate, and protease inhibitors) as previously described [57]. Proteins were quantified with a BCA assay, separated by SDS-10\% PAGE ( $\mu \mathrm{g} /$ lane as indicated in the figures) and blotted onto PVDF membranes. Membranes were probed with rabbit $\alpha_{2 \mathrm{~A}}$ adrenergic receptor polyclonal antibody (1:250, PA1-048, Invitrogen, Thermo Fisher Scientific, Waltham, MA, USA) and with mouse $\alpha_{2 C}$ adrenergic receptor monoclonal antibody (1:500, S330A-80, Invitrogen, Thermo Fisher Scientific) overnight at $4{ }^{\circ} \mathrm{C}$. Membranes were then incubated for $1 \mathrm{~h}$ at room temperature with the appropriate horseradish peroxidase-linked secondary antibodies (1:5000, A9044 and A9169, Sigma-Aldrich, St. Louis, MO, USA). Immunoblots were visualized using an ECL (enhanced chemiluminescence) Western blotting detection system. Images were acquired using the Alliance LD6 images capture system (Uvitec, Cambridge, UK) and analysed by UVI-1D software (Uvitec, Cambridge, UK). 


\subsection{Statistical Analysis}

For data handling/statistics and graph drawing, the SigmaPlot 10 data analysis and graphing software package was used. Multiple comparisons were performed with analysis of variance (ANOVA) followed by Tukey's multiple-comparisons test. Data were considered significant for $p<0.05$ at least.

\subsection{Chemicals}

Noradrenaline, levo $\left[7_{-}^{3} \mathrm{H}\right]$ (specific activity $12.1 \mathrm{Ci} / \mathrm{mmol}$ ), was from Perkin Elmer (Boston, MA, USA). Ellagic acid, yohimbine, clonidine and 6-nitroquipazine were from Sigma Aldrich. Western blotting detection system Immobilon Forte Western HRP substrate was from Merck (Darmstad, Germany).

\section{Results and Discussion}

\subsection{Computational Studies}

In silico studies were carried out to explore the binding modes of EA into $\alpha_{2 \mathrm{~A}}$-ARs and $\alpha_{2 C}-A R$ catalytic pockets. In addition to this, these specific docking studies were carried out to investigate the possible differences and similarities of the interactions established between a known agonist (clonidine) or antagonist (yohimbine) with the receptors. For the current analysis, the crystal structures of the human $\alpha_{2 \mathrm{~A}}-\mathrm{AR}$ in complex with the indole derivative, a partial agonist (PDB code: $6 \mathrm{KUY}$ ) [36], $\alpha_{2 \mathrm{~A}}-\mathrm{AR}$ in complex with the naphthyridine derivative, an antagonist (PDB code: 6KUX) [58], and, $\alpha_{2 C}-\mathrm{AR}$ in complex with the naphthyridine derivative, an antagonist (PDB code: 6KUW [37], were used.

\subsubsection{Molecular Docking Studies}

For each structure, the docking protocol was validated by docking the co-crystallized ligand into the binding site (Figure $3 a, b)$. Root mean square deviation (RMSD) values between the native pose of $\alpha_{2 \mathrm{~A}}-\mathrm{AR}_{6 \mathrm{KU}}, \alpha_{2 \mathrm{~A}}-\mathrm{AR}_{6 \mathrm{KUX}}$ and $\alpha_{2 \mathrm{C}}-\mathrm{AR} 6_{\mathrm{KUW}}$ ligands and the related best re-docked conformations were found to be $0.19 \AA$ (Figure 3c), $0.89 \AA$ (Figure 3d), and $0.39 \AA$ (Figure 3e), respectively, thus revealing the reliability of docking protocol (Figure $3 \mathrm{a}-\mathrm{c}$ ).

The three ligands were docked to the minimized structures of the $\alpha_{2}$-ARs subtypes $A$ and $C$, respectively (Table 1 ). Regarding yohimbine in complex to $\alpha_{2 A}-A_{6 K U X}$, it was observed that it was able to better recognize the orthosteric pocket of the receptor, compared to EA and clonidine. In detail, the positively charged amine group in the pyrido[1,2-b]isoquinoline displays a hydrogen bond with D113 (1.81 $⿱$ ) and a $\pi$-cation interaction with F412. The hydroxyl and the carboxylic group create a hydrogen bond with Y98 side chain and I190 backbone, respectively. Furthermore, the indole moiety enhances the binding by two $\pi-\pi$ interactions with F390 and F391 (Figure 4g-i).

The peculiar structure of the EA is buried in a hydrophobic core formed by Y98, Y109, I190, F390, Y394, F408, F412 and Y416 residues (Figure 4f). The receptor-ligand interaction is then stabilized by H-bond interactions between the hydroxyl groups of the two gallic acid motifs and the side chains of D113 and E189, which lie on the extracellular loop 2 (XL2), directly linked to the TM5 [35]. Furthermore, a $\pi-\pi$ interaction occurs in proximity with the receptor exterior, between F408 and one of the aryl rings; meanwhile, the oxygen of the carbonyl group of the EA forms the hydrogen bond with the hydroxyl group of Y98 (Figure $4 \mathrm{~d}, \mathrm{e}$ ).

Clonidine docking pose shows a very similar orientation to that of the EA into the $\alpha_{2 \mathrm{~A}}-\mathrm{AR}_{6 \mathrm{KUX}}$ binding cavity, thus pointing the positive charge of the imidazole ring towards D113 and F412, through a H-bond and a $\pi$-cation interaction, respectively, acting as an anchor within the binding site (Figure $4 \mathrm{a}-\mathrm{c}$ ). 
a)

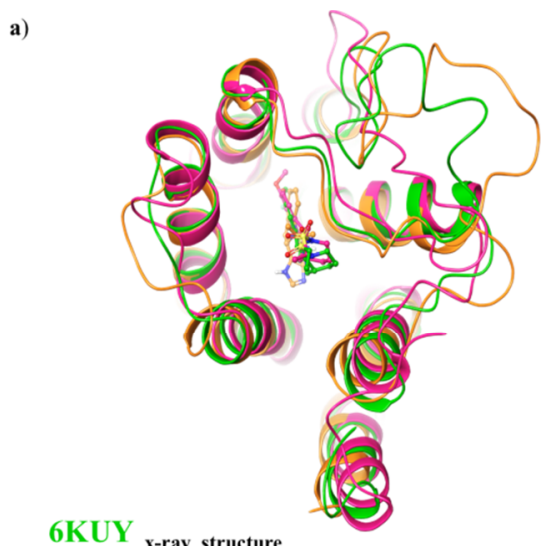

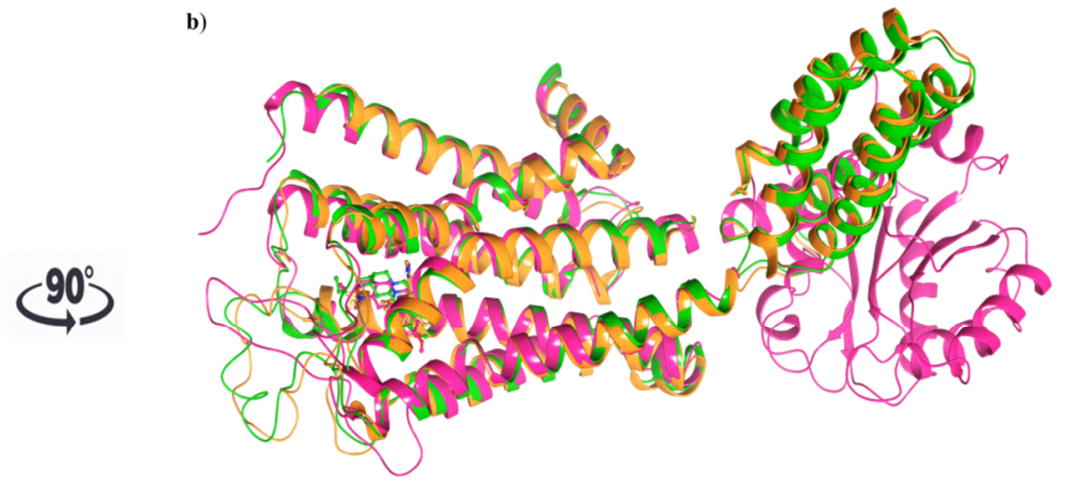

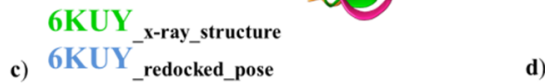

d) $6 \mathrm{KUX}_{\text {redocked_pose }}{ }_{\text {reray_structure }}$

6KUW_x-ray_structure

e) $6 \mathrm{KUW}_{\text {redocked_pose }}^{-}$

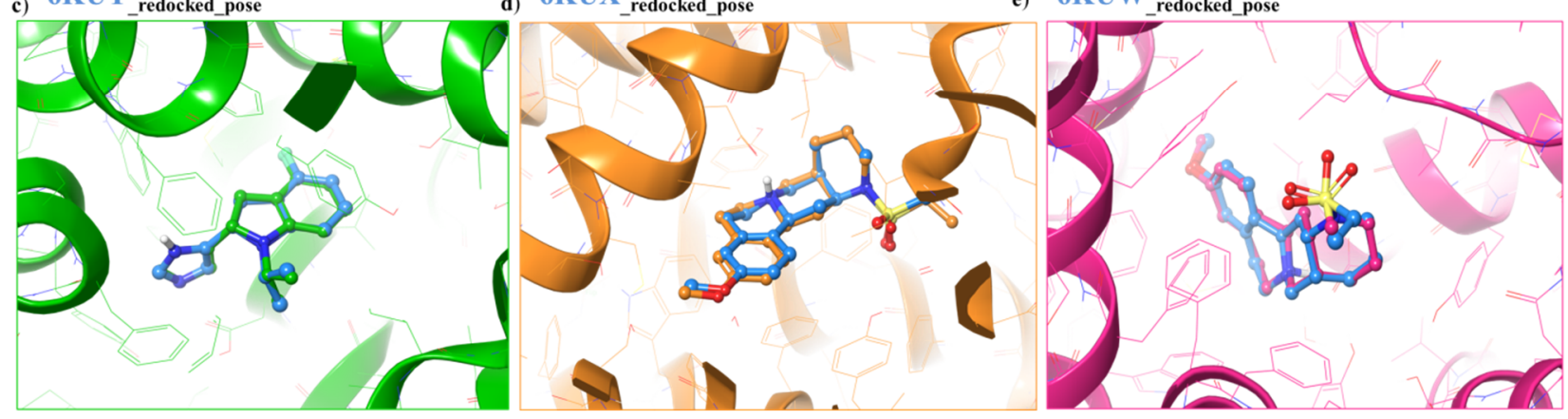

Figure 3. (a) Top view: Ribbon representation of overlaid binding orientation of co-crystallized ligands into the binding site of $\alpha_{2 \mathrm{~A}}-\mathrm{AR}_{6 \mathrm{KUY}}$ (orange), $\alpha_{2 \mathrm{~A}}-\mathrm{AR}_{6 \mathrm{KUX}}$ (green) and $\alpha_{2 \mathrm{C}}-\mathrm{AR}_{6 \mathrm{KUW}}$ (magenta) structures; (b) Front view of the superposed $\alpha_{2 A-C}-A R S s$. Three-dimensional superimposition between the re-docked pose (blue carbon ball and sticks) and the conformation of the native ligand; (c) Indole derivative into the binding site of 6KUY; (d) Naphthyridine derivative into both 6KUX (green) and (e) 6KUW (magenta) X-ray structures.

Table 1. Glide score, calculated in $\mathrm{kcal} / \mathrm{mol}$, of the best yohimbine, EA and clonidine docked pose towards $\alpha_{2 \mathrm{~A}}-\mathrm{AR}_{6 \mathrm{KUX}}, \alpha_{2 \mathrm{~A}}-\mathrm{AR}_{6 \mathrm{KUY}}$ and $\alpha_{2 \mathrm{C}}-\mathrm{AR}_{6 \mathrm{KUW}}$ structures.

\begin{tabular}{cccc}
\hline & $\alpha_{\mathbf{2 A}}-\mathbf{A R}_{\mathbf{6 K U X}}$ & $\alpha_{\mathbf{2 A}}-\mathbf{A R}_{\mathbf{6 K U Y}}$ & $\alpha_{\mathbf{2 C}}-\mathbf{A R}_{\mathbf{6 K U W}}$ \\
\cline { 2 - 4 } & Glide SP Score $^{*}$ & Glide SP Score $^{*}$ & Glide SP Score $^{*}$ \\
\hline Yohimbine & -7.86 & -7.62 & -9.12 \\
EA & -6.56 & -7.43 & -5.61 \\
Clonidine & -4.85 & -6.02 & -4.39 \\
\hline
\end{tabular}

* Glide SP score is calculated in $\mathrm{kcal} / \mathrm{mol}$.

Although $\alpha_{2 \mathrm{~A}}-\mathrm{AR}_{6 \mathrm{KUX}}$ and $\alpha_{2 \mathrm{~A}}-\mathrm{AR}_{6 \mathrm{KUY}}$ are characterized by a different rearrangement of the side chains of the hydrophobic residues into the binding pocket, the indole moiety of the yohimbine into $\alpha_{2 \mathrm{~A}}-\mathrm{AR}_{6 \mathrm{KUY}}$ can create a $\pi-\pi$ interaction with F412 and W438 (Figure $5 \mathrm{~g}-\mathrm{i}$ ). Instead, EA interacts with F391 and $\mathrm{Y} 394$ by means of one gallic acid motif (Figure $5 \mathrm{~d}-\mathrm{f}$ ). When clonidine is docked to $\alpha_{2 \mathrm{~A}}-\mathrm{AR}_{6 \mathrm{KUY}}$, the 2-aminoimidazoline group forms two hydrogen bonds with D113, and a $\pi$-cation interaction with F390, while the dichlorophenyl ring stretches towards the extracellular solvent to bind the Y394 residue (Figure $5 \mathrm{a}-\mathrm{c}$ ).

Concerning the $\alpha_{2 C}-\mathrm{AR}_{6 \mathrm{KUW}}$ subtype, docking analysis highlights that yohimbine forms a conserved salt bridge with the carboxylate of D131 and, also, a $\pi$-cation interaction with F423 and F391 (Figure 6a-c). 


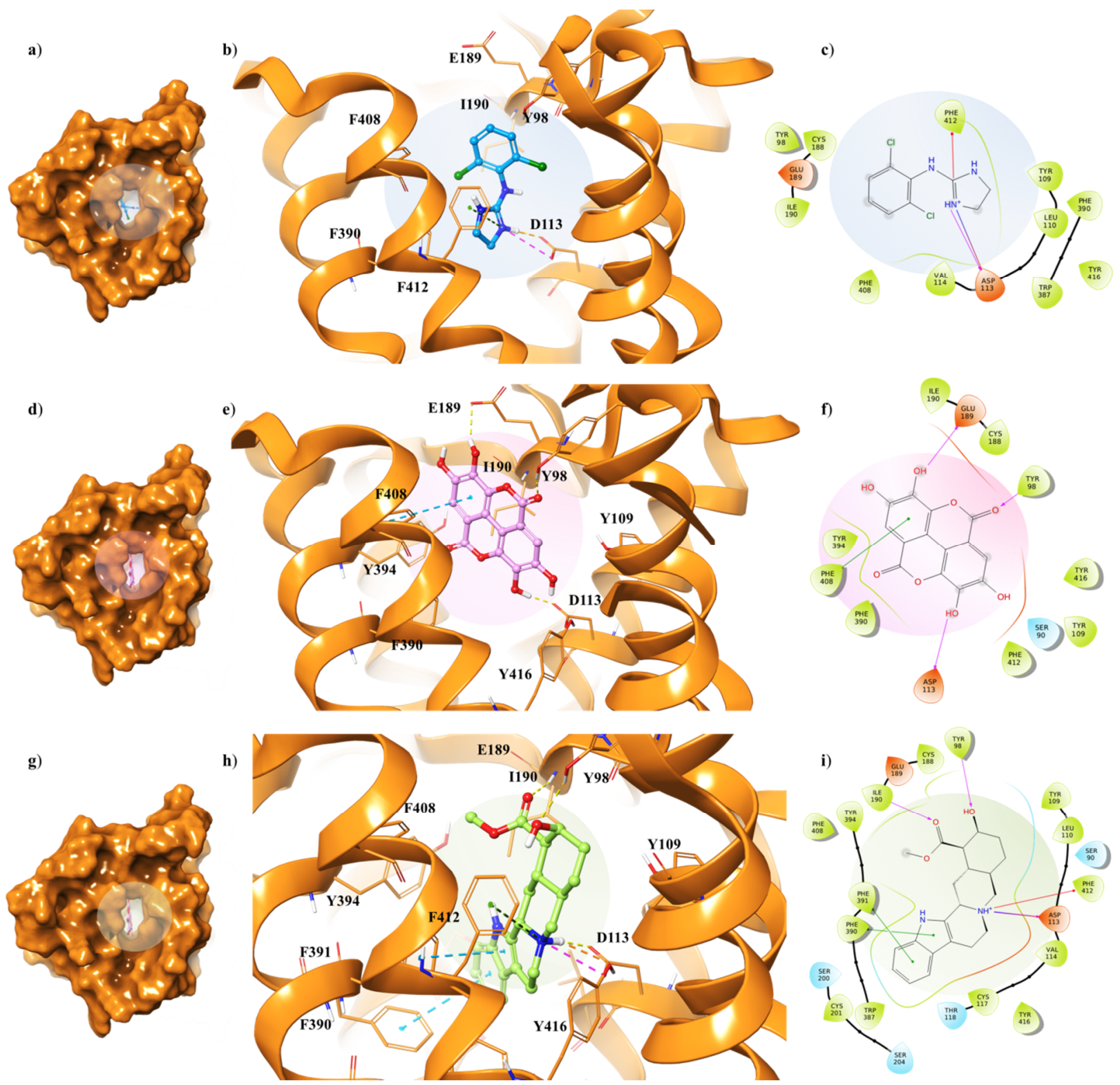

Figure 4. Key contacting elements inside (a-c) the $\alpha_{2 \mathrm{~A}}-\mathrm{AR}_{6 \mathrm{KUX}} /$ clonidine, $(\mathbf{d}-\mathbf{f})$ the $\alpha_{2 \mathrm{~A}}-\mathrm{AR}_{6 \mathrm{KUX}} / \mathrm{EA}$, and $(\mathbf{g}-\mathbf{i})$ the $\alpha_{2 \mathrm{~A}}-$ $\mathrm{AR}_{6 \mathrm{KUX}} /$ yohimbine best docked pose. Panels (b,e,h) show all side chains involved in $\mathrm{H}$-bonds (violet), $\pi-\pi$ interactions (cyan) and $\pi$-cation interactions (red) in stick representation. Panels (a,d,g) show the surface area of $\alpha_{2 \mathrm{~A}}-\mathrm{AR}_{6 \mathrm{KUX}}$ complexed to clonidine, EA and yohimbine, respectively. The surface area of the receptor is shown in solid orange solid. $2 \mathrm{D}$ representation of the key interactions of (c) clonidine, (f) EA and (i) yohimbine into the $\alpha_{2 \mathrm{~A}}-\mathrm{AR}_{6 \mathrm{KUY}}$ structure.

The antagonist is surrounded by nine aromatic residues (Y127, Y210, W395, F398, F399, Y402, F419, F423, Y427) on TM6 and TM7, and three other residues (L128, V132, L204) forming the hydrophobic environment of the binding cavity. The indole moiety interacts with F398 and F399 by means of two $\pi-\pi$ interactions, while the carboxyl group engages a H-bond with L204, one of the pivotal residues in establishing subtype selectivity [47].

EA is well accommodated into the $\alpha_{2 C}$-AR pocket and interacts with the same residues with which yohimbine interacts, except that one hydroxyl group of EA is in contact with N111 (Figure 6d-f). Finally, analysing the interactions between clonidine and $\alpha_{2 C}-A_{6 K U W}$, it is noted that the 2-aminoimidazoline group creates two hydrogen bonds with D131, and then the dichlorophenyl ring is stabilized by two $\pi-\pi$ interactions with F398 and Y402 (Figure 6g-i). 

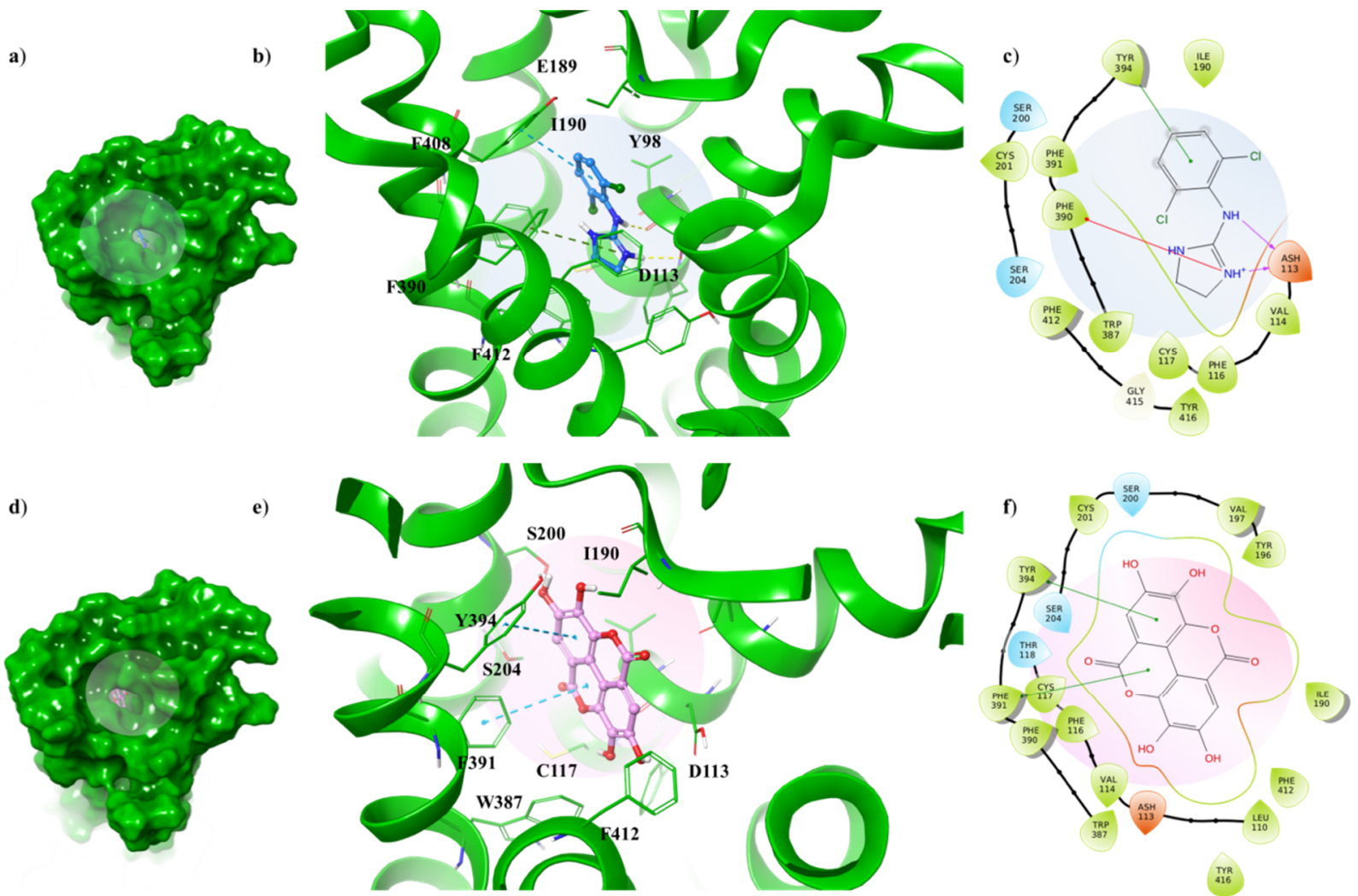

g)

h)
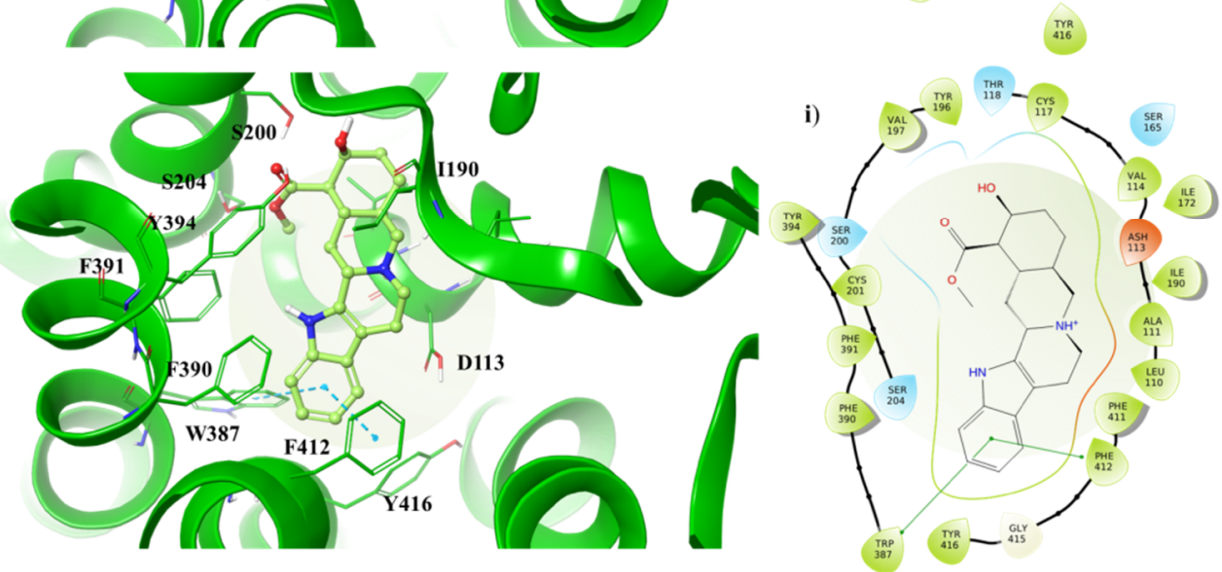

Figure 5. Key contacting elements inside $(\mathbf{a}-\mathbf{c})$ the $\alpha_{2 \mathrm{~A}}-\mathrm{AR}_{6 \mathrm{KUY}} /$ clonidine, $(\mathbf{d}-\mathbf{f})$ the $\alpha_{2 \mathrm{~A}}-\mathrm{AR}_{6 \mathrm{KUY}} / \mathrm{EA}$, and $(\mathbf{g}-\mathbf{i})$ the $\alpha_{2 \mathrm{~A}}-$ $\mathrm{AR}_{6 \mathrm{KUY}} /$ yohimbine best docked pose. Panels $(\mathbf{b}, \mathbf{e}, \mathbf{h})$ show all side chains involved in $\mathrm{H}$-bonds (violet), $\pi-\pi$ interactions (cyan) and $\pi$-cation interactions (red) in stick representation. Panels $(\mathbf{a}, \mathbf{d}, \mathbf{g})$ show the surface area of $\alpha_{2 \mathrm{~A}}-\mathrm{AR}_{6 \mathrm{KUY}}$ complexed to clonidine, EA and yohimbine, respectively. The surface area of the receptor is shown in solid green. $2 \mathrm{D}$ representation of the key interactions of (c) clonidine, (f) EA and (i) yohimbine into the $\alpha_{2 \mathrm{~A}}-\mathrm{AR}_{6 \mathrm{KUY}}$ structure.

\subsubsection{MDs of EA Complexed with $\alpha_{2}$-ARs}

For each complex, the best docked pose of EA, yohimbine and clonidine into $\alpha_{2}-$ ARs binding pockets were chosen as the starting point for $50 \mathrm{~ns}$ of molecular dynamics simulations (MDs). MDs results were investigated in terms of stability of the complexes and conformational flexibility of $\alpha_{2}$-ARs in presence of the EA, with respect to the partial agonist and the antagonist, such as the clonidine and the yohimbine, respectively, by monitoring the single contributions of hydrophobic, water bridges and hydrogen bonding interactions.

In order to hypothesize the partial agonist or antagonist activity of EA, based on the importance of the interaction with aspartic acid on TM3 and the serine residues contained in TM5, as reported in previous studies [48], we monitored the distance between the centroid atom of EA, clonidine and yohimbine structures and the $\mathrm{C} \alpha$ of these critical residues, in $\alpha_{2 \mathrm{~A}}$ (D113, S200, S204) and $\alpha_{2 C}$ (D131, S214, S218) adrenoreceptors. Particularly, for the 
$\alpha_{2 \mathrm{~A}}-\mathrm{AR}$ structure, a lower distance between EA and S200 was found with respect to that of clonidine and yohimbine (Figure $7 \mathrm{a}$ ), with the average values equal to $7.3 \AA$, $10.0 \AA$ and $10.8 \AA$, respectively. As already understood, S200 and S204 play a crucial role in the activation of aminergic GPCRs such as the $\alpha_{2}$-AR. The lack of flexibility of EA and its peculiar structure with hydrophobic core and hydrophilic ends allow it to reside in the TM5 area, which may be the cause of its partial agonism compared to the antagonist profile of yohimbine, which seems to move away from the TM5 in the last $10 \mathrm{~ns}$ of dynamics. Meanwhile, for the $\alpha_{2 C}$-AR structure, all three investigated compounds remain stable in the orthosteric binding pocket (Figure $7 \mathrm{~b}$ ). No significant differences can be observed, except for EA which seems to be prone towards S214 at the end of the MDs.

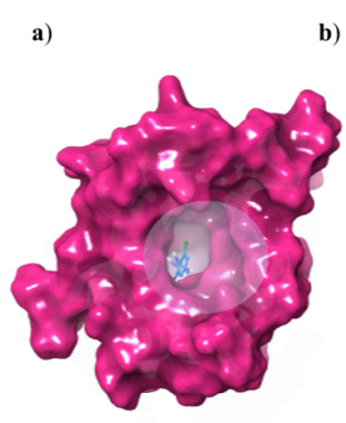

b)
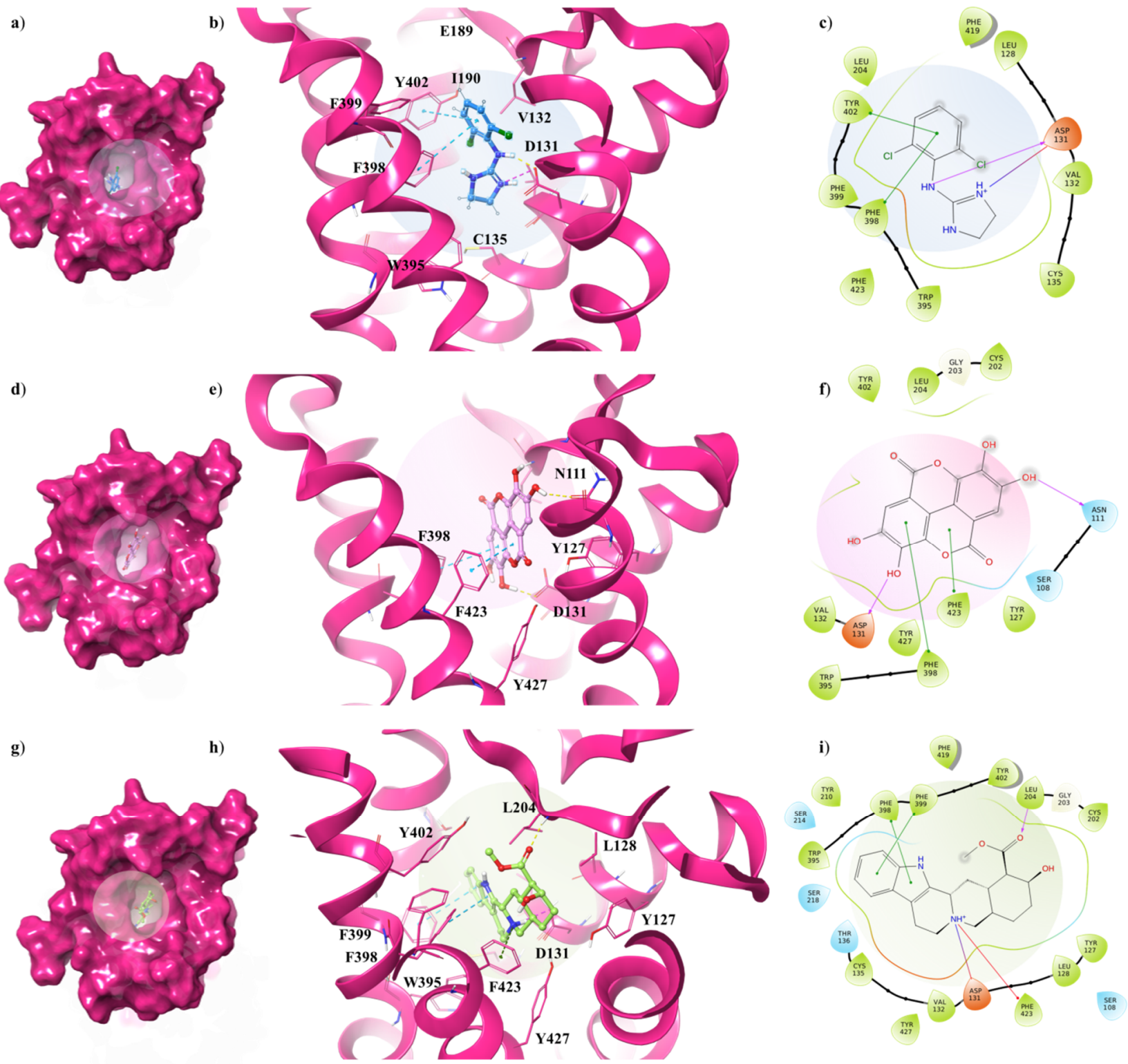

Figure 6. Key contacting elements inside $(\mathbf{a}-\mathbf{c})$ the $\alpha_{2 \mathrm{~A}}-\mathrm{AR}_{6 \mathrm{KUW}} /$ clonidine, $(\mathbf{d}-\mathbf{f})$ the $\alpha_{2 \mathrm{~A}}-\mathrm{AR}_{6 \mathrm{KUW}} / \mathrm{EA}$, and $(\mathbf{g}-\mathbf{i})$ the $\alpha_{2} \mathrm{~A}-$ $\mathrm{AR}_{6 \mathrm{KUW}} /$ yohimbine best docked pose. Panels (b,e,h) show all side chains involved in $\mathrm{H}$-bonds (violet), $\pi-\pi$ interactions (cyan) and $\pi$-cation interactions (red) in stick representation. Panels $(\mathbf{a}, \mathbf{d}, \mathbf{g})$ show the surface area of $\alpha_{2 \mathrm{~A}}-\mathrm{AR}_{6 \mathrm{KUW}}$ complexed to clonidine, EA and yohimbine, respectively. The surface area of the receptor is shown in solid magenta. $2 \mathrm{D}$ representation of the key interactions of (c) clonidine, (f) EA and (i) yohimbine into $\alpha_{2 \mathrm{~A}}-\mathrm{AR}_{6 \mathrm{KUY}}$ structure. 

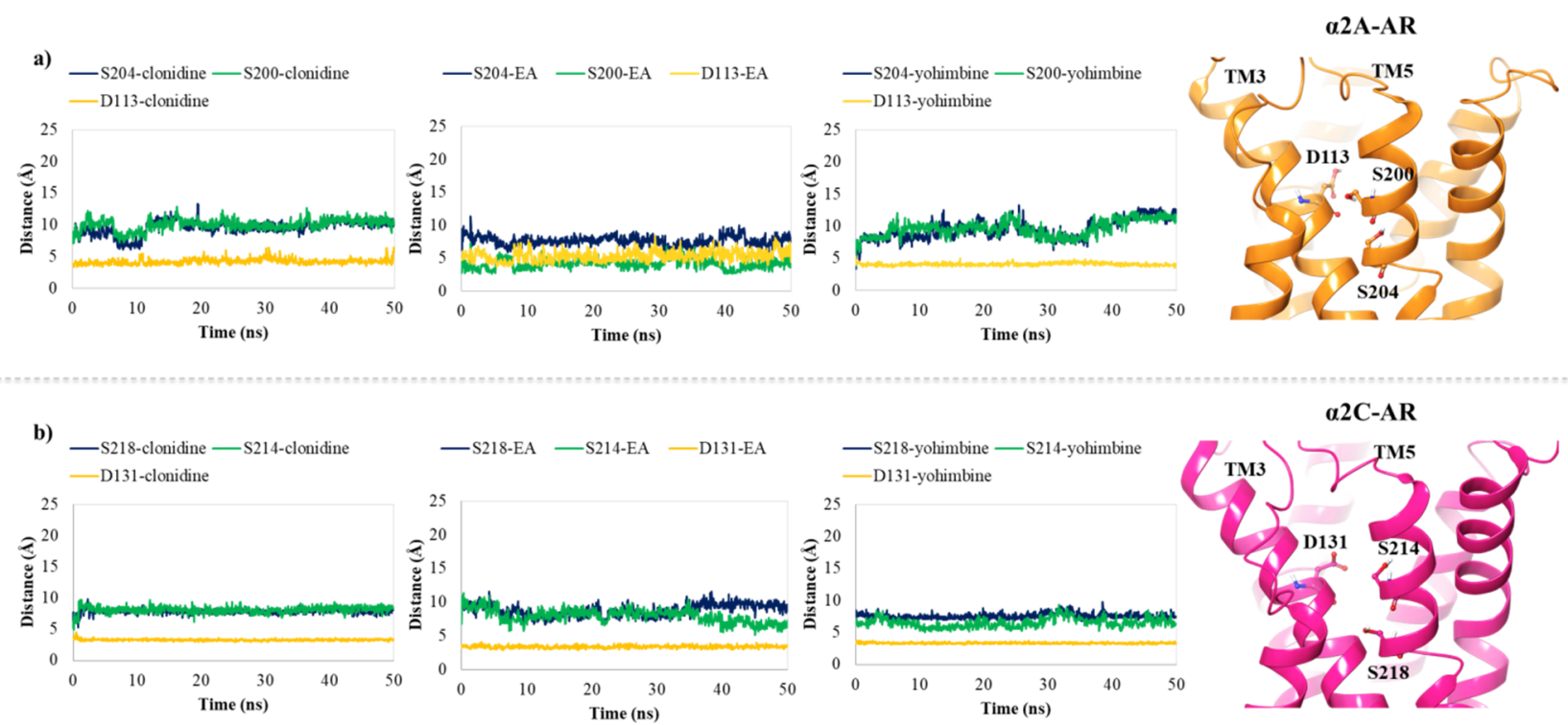

Figure 7. Plots of the distances between the centroid atom of EA, clonidine and yohimbine and (a) D113 (orange), S200 (green) and S204 (blue) into the $\alpha_{2 \mathrm{~A}}$-AR structure; (b) D131 (orange), S214 (green), and S218 (blue) into the $\alpha_{2 C}$-AR structure, throughout $50 \mathrm{~ns}$ of MDs. Right-hand images show zoomed-in context of the pivotal residues, depicted in orange and magenta carbon ball and sticks, involved in the $\alpha_{2 \mathrm{~A}}-\mathrm{AR}$ and $\alpha_{2 \mathrm{C}}-\mathrm{AR}$ binding pockets, respectively.

Taking into account the dynamic behaviour of EA into the $\alpha_{2 \mathrm{~A}}-\mathrm{AR}_{6 \mathrm{KUX}}$ structure with respect to the agonist and the antagonist, it is noticed that EA shifts towards R405 to form a $\pi$-cation interaction for $31 \%$ of MDs, losing the initial binding to D113. Its hydroxyl groups bind S90 and Y109 for 24\% and 25\% of MDs, respectively. Trajectories of clonidine and yohimbine present some similarities, such as their ability to interact with D113, Y394 and $\mathrm{F} 412$ residues, with an additional water bridge and $\mathrm{H}$-bond with the E189 $(36 \%)$ and I190 (95\%) for the yohimbine in the complex with $\alpha_{2 \mathrm{~A}}-\mathrm{AR}_{6 \mathrm{KUX}}$. Meanwhile, S200, which belongs to the TM5, stabilizes the clonidine into the $\alpha_{2 \mathrm{~A}}-\mathrm{AR}_{6 \mathrm{KUX}}$ pocket by means of a water-bridge for $46 \%$ of MDs, underlining the key binding elements in common to the endogenous ligands and, consequently, its role as a partial agonist.

Curiously, even if EA is not able to maintain the interaction with D113, it is well stabilized during the whole trajectory in the complex with the $\alpha_{2 \mathrm{~A}}-\mathrm{AR}_{6 \mathrm{KUY}}$ structure. Its conformational restraint provided by the hydrophobic core and the presence of the four hydroxyl groups results in a stronger binding affinity to drive EA within the $\alpha_{2 \mathrm{~A}}-\mathrm{AR}_{6 \mathrm{KUY}}$ pocket for a good anchoring system than that of both the partial agonist and antagonist structures. Indeed, aromatic residues such as F116 and F390 form $\pi-\pi$ interactions with the gallic acid motifs of EA for 38\% and 98\% of MDs. Moreover, S204, F408, F410 and F412 residues show a water-bridge interaction for around $30-60 \%$ of the trajectory. Regarding clonidine- $\alpha_{2 \mathrm{~A}}-\mathrm{AR}_{6 \mathrm{KUY}}$ complex MDs, the 2-aminoimidazoline group binds D113 (30\%) and F414 (33\%) through an H-bond and a $\pi$-cation interaction, respectively. Additionally, the dichlorophenyl ring is oriented between Y394 and F391, engaging $\pi-\pi$ interactions for a half run of MDs. Instead, analysing MDs of yohimbine- $\alpha_{2 A}-A_{6 K U Y}$, its major flexibility allows maintenance of the interaction between the positively charged amine group in the pyrido[1,2-b]isoquinoline and D113 (38\%) and L110 (53\%) residues. This moiety also forms the successful anchoring $\pi-\pi$ interaction with the phenylalanine at position 390 and 391 for $34 \%$ and $45 \%$ of MDs, respectively.

Conversely, all the three investigated compounds interact with similar but non identical subsets of residues in the $\alpha_{2 \mathrm{C}}$-AR structure. In particular, during the whole simulation, it can be observed that the 2-aminoimidazoline group of clonidine, the pyrido[1,2b]isoquinoline of the yohimbine, and the two hydroxyl groups of one gallic acid motif of EA participate in the pivotal interaction with the side chain oxygens of D131 (Figure 5b), which is involved in adrenergic signalling for $96 \%, 99 \%$ and $99 \%$ of MDs, respectively. Y402 
also provides a significant $\pi$-cation with clonidine (48\%) and $\pi-\pi$ interactions with both EA ( $40 \%)$ and yohimbine ( $42 \%)$. One gallic motif in EA displays two $\pi$-cation interactions with $\mathrm{K} 420$ for $55 \%$ and $31 \%$ of MDs. Carefully looking at yohimbine accommodation into the $\alpha_{2 \mathrm{C}}$-AR pocket during MDs, it appears that the indole moiety and the carboxyl group participate in major interactions with F398 (57\%), and L204 (65\%), respectively. Moreover, the hydroxyl group of yohimbine displays one water bridge with E112 (54\%).

Finally, the binding free energies calculated by carrying out the MM/GBSA method, known to be one of the rigorous and efficient methods to predict relative binding affinities, has been useful for evaluating the strength of EA's affinity over the $\alpha_{2}$-ARs binding pocket [49-59]. In this way, 1000 snapshots from $50 \mathrm{~ns}$ of MDs are extracted for the binding free energy calculations of both the $\alpha_{2}$-ARs-EA complex and the known partial agonist and antagonist in complex to $\alpha_{2}$-ARs $[60,61]$. The results of the calculated free energy trends for EA, in comparison with clonidine and yohimbine, are reported in Figure 8a-c.

MM/GBSA analysis reveals that the average calculated binding free energies $\left(\Delta \mathrm{G}_{\text {bind }}\right)$ of EA, clonidine and yohimbine complexed with $\alpha_{2 \mathrm{~A}}-\mathrm{AR}_{6 \mathrm{KUX}}$ (Figure 7a) are -57.02 , -54.86 and $-60.69 \mathrm{kcal} / \mathrm{mol}$, respectively, during the whole trajectories. Looking at the MM/GBSA trend, it can be seen that EA may behave like a partial agonist, strengthening its non-bonded interactions throughout MDs. Instead, the average values of -75.22 , $-56.41,-66.89 \mathrm{kcal} / \mathrm{mol}$ are calculated for EA, clonidine and yohimbine into $\alpha_{2 \mathrm{~A}}-\mathrm{AR}_{6 \mathrm{KUY}}$, respectively, thus resulting in a more stabilizing effect of EA over the pocket of $\alpha_{2 \mathrm{~A}}$-ARs (Figure $7 \mathrm{~b}$ ). In the $\alpha_{2 \mathrm{C}}-\mathrm{AR}_{6 \mathrm{KUW}}$, the MM/GBSA trend shows that yohimbine is associated to the higher binding free energies than that of both clonidine and EA, with average values equal to $-64.88,-54.29$ and $-42.00 \mathrm{kcal} / \mathrm{mol}$, respectively (Figure $8 \mathrm{c}$ ).

\subsection{Pharmacological In Vitro Functional Studies}

\subsection{1. $\alpha_{2 \mathrm{~A}}$ and $\alpha_{2 \mathrm{C}}$ Receptor Proteins in Hippocampal Lysates}

The ascending noradrenergic projections from the Locus coeruleus to the hippocampus possess in their preterminal varicosities and terminals presynaptic inhibitory releaseregulating $\alpha_{2}$-ARs, as confirmed by the Western blot analysis of the mouse hippocampal lysates, which demonstrated the presence of the $\alpha_{2 \mathrm{~A}}$-AR (Figure 9A) and the $\alpha_{2 \mathrm{C}}-\mathrm{AR}$ (Figure 9B) proteins, having a mass consistent with the monomeric structure (45 kDa and $50 \mathrm{kDa}$ for the $\alpha_{2 \mathrm{~A}}$ and $\alpha_{2 \mathrm{C}}$ receptor proteins, respectively), but also of polymeric associations, particularly evident in the case of $\alpha_{2 \mathrm{~A}}-\mathrm{AR}$. The analysis unveiled a direct correlation between the intensity of the immune-positivities and the protein content loaded in each lane. We did not investigate the presence of the $\alpha_{2 B}-A R$ protein because of its preferential peripheral expression [28].

These results confirmed the presence of $\alpha_{2 \mathrm{~A}}-\mathrm{AR}$ and $\alpha_{2 \mathrm{C}}$-AR proteins in the hippocampus of adult mice, opening the possibility to focus on this brain region for in vitro functional studies to verify the intrinsic activity of EA on naïve $\alpha_{2}$-ARs.

3.2.2. Ellagic Acid Mimics Clonidine at the Presynaptic Release-Regulating $\alpha_{2}$ Autoreceptors in Hippocampal Noradrenergic Nerve Endings: Antagonism by Yohimbine

To verify, by a functional point of view, if naive $\alpha_{2}$ ARs could represent a specific cellular target of EA, we isolated synaptosomes from the hippocampus of adult male mice, and quantified in release experiments the impact of EA on the NA exocytosis. Experiments were carried out by using the technique of the "up-down superfusion of a thin layer of synaptosomes", which is widely recognized as an approach of choice to prove, by a functional point of view, the existence of receptors in nerve endings, and to pharmacologically characterize the affinity and the intrinsic activity of ligand(s) acting at selected naïve receptor subtypes (see for experimental and technical details in the Method section, Figure 2). 


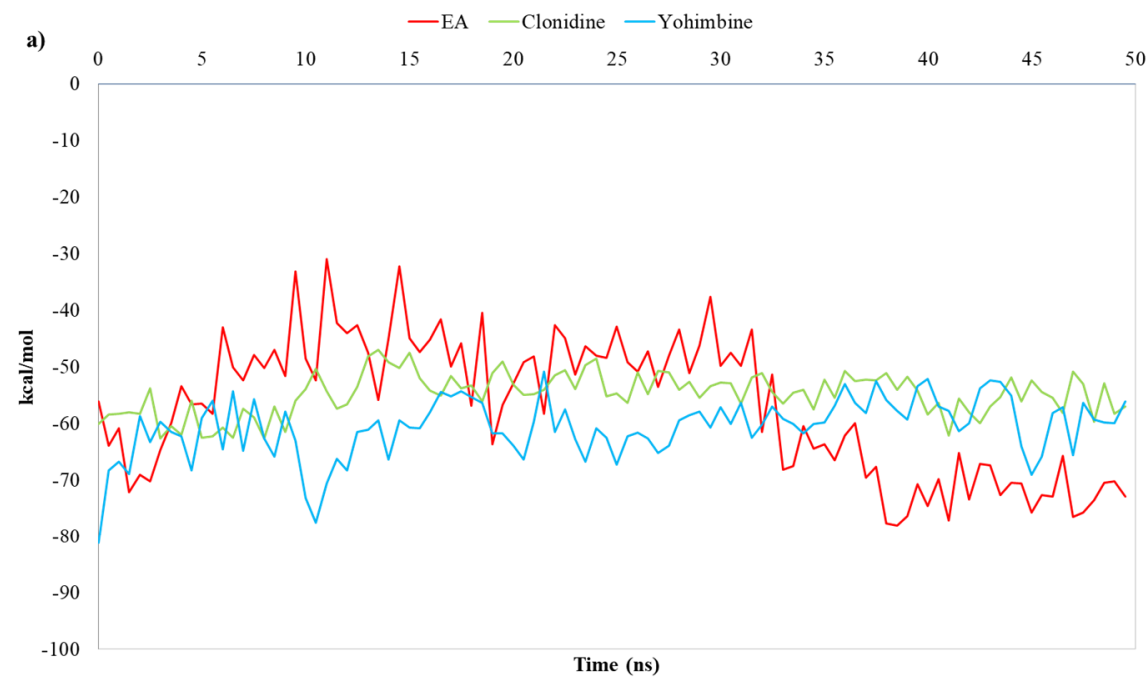

$2 \mathbf{A}^{\mathrm{A}}-\mathrm{AR}_{6 \mathrm{KUX}}$

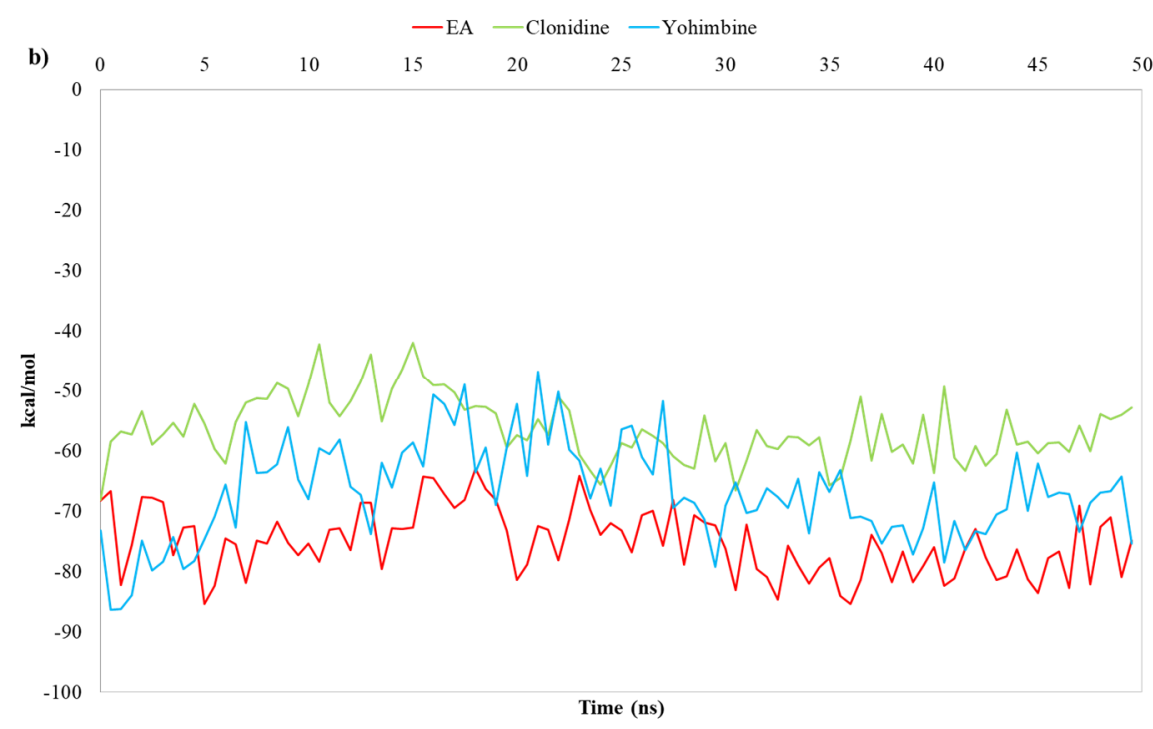

$\alpha 2 \mathrm{~A}^{-} \mathbf{A R}_{6 \mathrm{KUY}}$

$10 \quad 20$

40 50

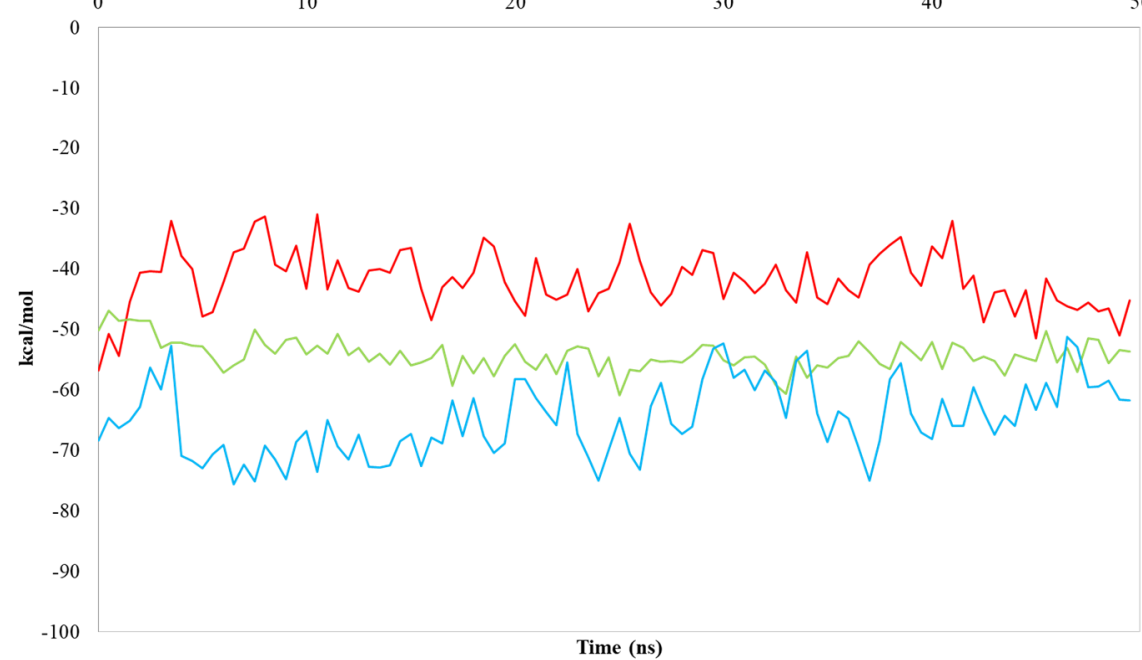

$\boldsymbol{\alpha 2 C}-\mathbf{A R}_{6 \mathrm{KUW}}$

Time (ns)

Figure 8. Plots of MM/GBSA trend for EA, clonidine and yohimbine in complex to (a) $\alpha_{2 A}-A R_{6 K U X}$, (b) $\alpha_{2 \mathrm{~A}}-\mathrm{AR}_{6 \mathrm{KUY}}$, and (c) $\alpha_{2 \mathrm{C}}-\mathrm{AR}_{6 \mathrm{KUW}}$, during 50 ns of MDs. 

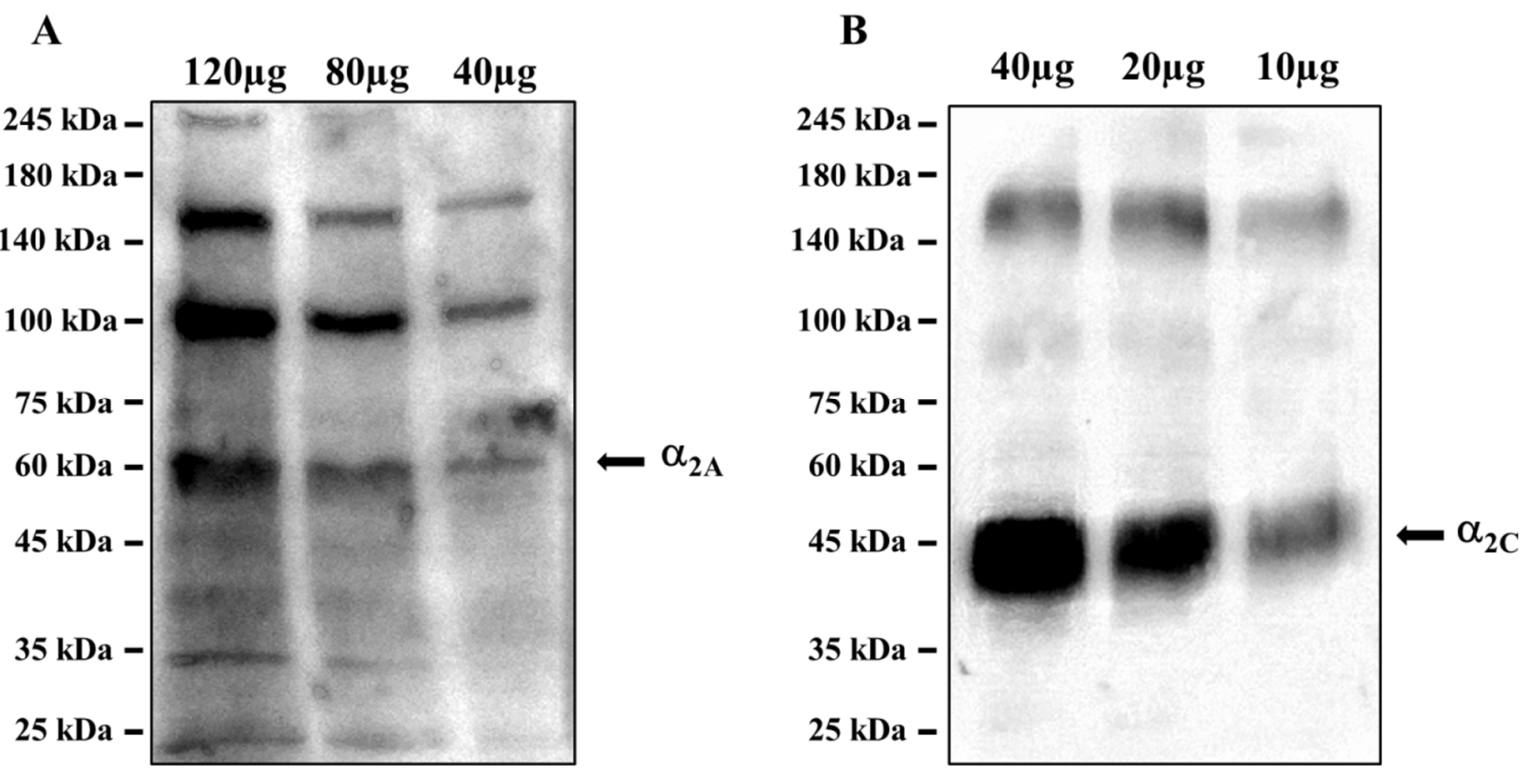

Figure 9. Mouse hippocampal lysates are endowed with (A) the $\alpha_{2 \mathrm{~A}}-\mathrm{AR}$ and (B) the $\alpha_{2 \mathrm{C}}-\mathrm{AR}$ proteins. The images are representative of three analyses run on different preparations. Protein weights are expressed in kDa.

Consistent with the inhibitory nature of the presynaptic $\alpha_{2}$-ARs, the exocytotic-like release of preloaded $\left[{ }^{3} \mathrm{H}\right] \mathrm{NA}$ elicited by $12 \mathrm{mM} \mathrm{KCl}$-enriched solution was significantly reduced $\left(-48.80 \%, n=4, p<0.05\right.$, result expressed as $\%$ of inhibition) when the $\alpha_{2}$-ARs agonist clonidine $(0.1 \mu \mathrm{M})$ was added concomitantly to the depolarizing stimulus. An almost comparable reduction of $\left[{ }^{3} \mathrm{H}\right] \mathrm{NA}$ exocytosis was observed when synaptosomes were exposed to the $\mathrm{KCl}$-enriched solution containing $10 \mathrm{nM} \mathrm{EA}(-36.80, n=5, p<0.05)$; a lower concentration $(1 \mathrm{nM})$ of the natural compound slightly, although not significantly $(-13.74, n=3$, n.s.), affected the tritium overflow (Figure 10a).

We asked whether the inhibitory effect elicited by EA involves the presynaptic releaseregulating $\alpha_{2}$-ARs. To answer the question, yohimbine, a selective $\alpha_{2}$ autoreceptor antagonist, was added concomitantly to EA $(10 \mathrm{nM})$ to compete with the natural compound for the binding at the presynaptic $\alpha_{2}$-AR. It is worth reminding that this drug, unable on its own to affect the tritium exocytosis, efficiently recovers the inhibitory effect elicited by clonidine on the $12 \mathrm{mM} \mathrm{KCl}$-evoked tritium release (not shown but see $[20,23,54,56,62-64]$ ). Accordingly, yohimbine (1-100 nM) prevented, in a concentration-dependent fashion, the inhibitory effect elicited by $10 \mathrm{nM}$ EA (Figure 10b).

On the whole, these functional observations demonstrate that EA activates naïve presynaptic release-regulating $\alpha_{2}$-ARs in hippocampal noradrenergic nerve endings. The natural compound mimics clonidine, behaving as an agonist at the naïve $\alpha_{2}$-ARs receptors. The agonist-like intrinsic activity of EA at these receptors is confirmed by the finding that the $\alpha_{2}$-AR antagonist yohimbine, devoid of intrinsic regulatory activity, prevents the agonist-like activity of EA at the naïve $\alpha_{2}$-ARs. 
a)

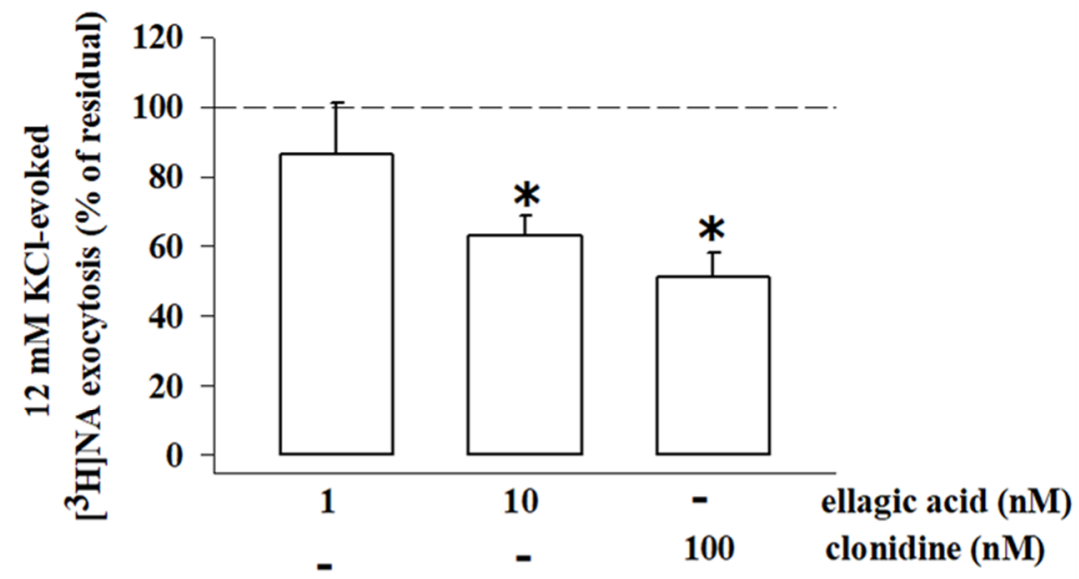

b)

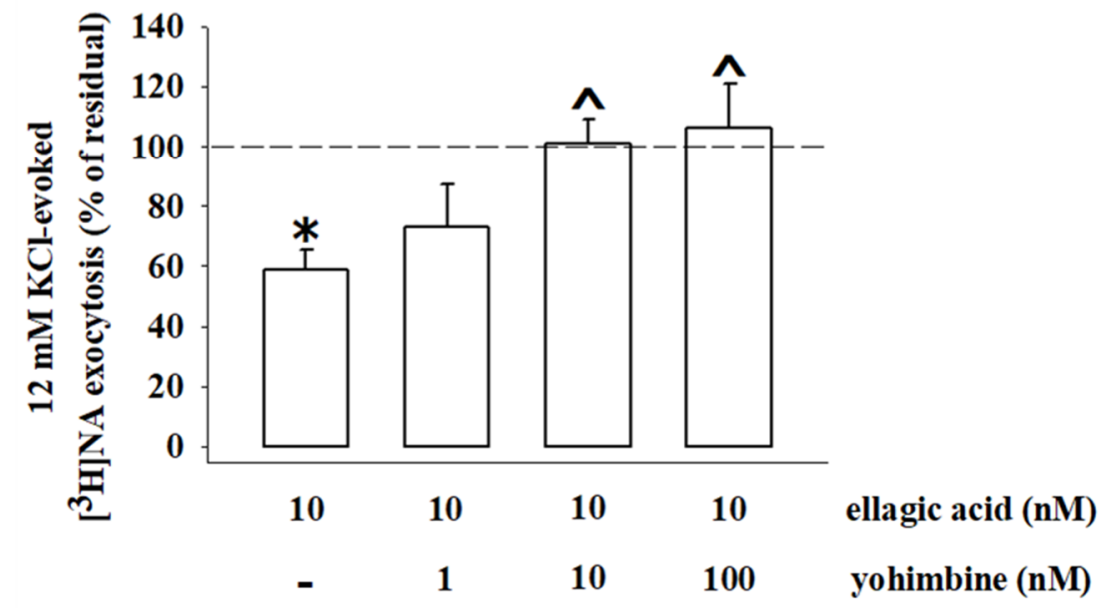

Figure 10. Ellagic acid mimics clonidine in inhibiting the ${ }^{3}[\mathrm{H}]$ noradrenaline $\left({ }^{3}[\mathrm{H}] \mathrm{NA}\right)$ exocytosis from mouse hippocampal synaptosomes, and its effect is reversed by yohimbine. (a) Effects of ellagic acid (1 and $10 \mathrm{nM})$ and clonidine $(100 \mathrm{nM})$ on the $12 \mathrm{mM} \mathrm{KCl-evoked}{ }^{3}[\mathrm{H}] \mathrm{NA}$ release from mouse hippocampal synaptosomes. (b) Effect of ellagic acid (10 nM), alone or concomitantly added with yohimbine (1-100 nM), on the $12 \mathrm{mM} \mathrm{KCl-evoked}{ }^{3}[\mathrm{H}] \mathrm{NA}$ release from mouse hippocampal synaptosomes. Results are expressed as percentage of residual of the $12 \mathrm{mM} \mathrm{KCl-evoked} \mathrm{tritium}$ release. Data represent the means $\pm \mathrm{SEM}$ of four to five experiments run in triplicate. ${ }^{*} p<0.05$ versus $12 \mathrm{mM} \mathrm{KCl}$-induced tritium overflow; ^ $p<0.05$ versus $12 \mathrm{mM} \mathrm{KCl} / 10 \mathrm{nM}$ ellagic acid-induced tritium overflow.

\section{Conclusions}

The peculiar structure of EA, characterized by a hydrophobic core and hydrophilic ends, led to its accommodation in the TM5 area, close to S200 and S204 which play a crucial role for activation of aminergic GPCRs, such as the $\alpha_{2}$-AR. Thermodynamic investigation revealed that EA is well stabilized into the $\alpha_{2 \mathrm{~A}}-\mathrm{AR}$ binding site, if compared to the known partial agonist and antagonist. These structural findings highlight the promising role of EA as a partial agonist. Despite the lack of a positive region in the EA structure able to anchor the acid group of a conserved aspartate residue, this natural compound shows strong interaction in the binding pockets of $\alpha_{2}$-AR. Indeed, by MDs and MM/GBSA analyses, the hydrophobic residues surrounding the $\alpha_{2 \mathrm{~A}}$-AR pocket confer specificity on the intermolecular interactions, and hence lead to favourable binding of EA in the $\alpha_{2 \mathrm{~A}}-\mathrm{AR}$, with respect to $\alpha_{2 \mathrm{C}}-\mathrm{AR}$.

The in silico conclusions were verified in functional studies carried out with the mouse hippocampal synaptosomes bearing naïve $\alpha_{2}$-ARs. The experiments confirmed that EA 
has an intrinsic activity at the naïve $\alpha_{2}$-ARs. EA behaved at these receptors as an agonist, efficiently inhibiting NA exocytosis. The intrinsic agonist activity of the natural compound was definitively proved by the finding that the $\alpha_{2}$-AR antagonist yohimbine concentrationdependently prevented the EA-mediated inhibition of NA exocytosis. Unfortunately, the lack of drugs able to discriminate between the $\alpha_{2 \mathrm{~A}}-\mathrm{AR}$ and the $\alpha_{2 \mathrm{C}}-\mathrm{AR}$ makes it impossible to characterize, by a functional point of view, the $\alpha_{2}$-AR subtype(s) involved in the EA-mediated control of NA exocytosis. Furthermore, the data so far available do not allow conclusion of whether EA acts as a partial or a full agonist at the presynaptic $\alpha_{2}$-ARs. Despite these limitations, the in vitro data confirms, by a functional point of view, that naive $\alpha_{2}$-ARs represent a specific site of action of EA. Taking into consideration the wide distribution of the $\alpha_{2}-\mathrm{ARa}$, it seems conceivable to confirm that these receptors would mediate both peripheral and central EA-induced effects potentially involved in the nutraceutical activities of this natural compound.

Author Contributions: Conceptualization, G.C., A.P. and R.B.; methodology, I.R., G.O., F.T.; software, I.R.; validation, I.R. and G.C.; formal analysis, G.V. and A.R.; investigation, I.R. and G.O.; resources, S.A. and A.P.; data curation, I.R. and G.C.; writing-original draft preparation, F.T., G.O. and I.R.; writing-review and editing, A.P.; visualization, S.A.; supervision, G.C.; project administration, I.R. and G.C. All authors have read and agreed to the published version of the manuscript.

Funding: This research received no external funding.

Institutional Review Board Statement: The study was conducted in accordance with the ARRIVE guidelines and the European Communities Parliament and Council Directive of 22 September 2010 (2010/63/EU) and with the Italian D.L. n. 26/2014. The experimental procedures were approved by the Local Committee for Animal Care and Welfare of the University of Genova, and the Italian Ministry of Health (DDL 26/2014 and previous legislation; protocol number $n^{\circ}$ 75F11.N.IMY), in line with the 3Rs principles (reduction, refinement and replacement).

Informed Consent Statement: Not applicable.

Data Availability Statement: The data presented in this study are available in the article.

Conflicts of Interest: The authors declare no conflict of interest.

\section{References}

1. Barbieri, M.; Heard, C.M. Isolation of punicalagin from Punica granatum rind extract using mass-directed semi-preparative ESI-AP single quadrupole LC-MS. J. Pharm. Biomed. Anal. 2019, 166, 90-94. [CrossRef] [PubMed]

2. Turrini, F.; Malaspina, P.; Giordani, P.; Catena, S.; Zunin, P.; Boggia, R. Traditional decoction and PUAE aqueous extracts of pomegranate peels as potential anti-tyrosinase ingredients. Appl. Sci. 2020, 10, 2795. [CrossRef]

3. Global Pomegranate Market Industry Trends, Sales, Supply, Demand, Analysis \& Forecast. 2017. Available online: https:/ / www.researchmoz.us/global-pomegranate-market-2017-industry-trends-sales-supply-demand-analysis-and-forecas t-to-2022-report.html (accessed on 17 November 2020).

4. Shahkoomahally, S.; Khadivi, A.; Brecht, J.K.; Sarkhosh, A. Chemical and physical attributes of fruit juice and peel of pomegranate genotypes grown in Florida USA. Food Chem. 2020, 342, 128302. [CrossRef]

5. Ifeanyichukwu, U.L.; Fayemi, O.E.; Ateba, C.N. Green Synthesis of Zinc Oxide Nanoparticles from Pomegranate (Punica granatum) Extracts and Characterization of Their Antibacterial Activity. Molecules 2020, 25, 4521. [CrossRef] [PubMed]

6. Zuccari, G.; Baldassari, S.; Ailuno, G.; Turrini, F.; Alfei, S.; Caviglioli, G. Formulation strategies to improve oral bioavailability of ellagic acid. Appl. Sci. 2020, 10, 3353. [CrossRef]

7. Ahmed, T.N.; Setzer, W.; Fazel Nabavi, S.; Erdogan Orhan, I.; Braidy, N.; Sobarzo-Sanchez, E.; Mohammad Nabavi, S. Insights into Effects of Ellagic Acid on the Nervous System: A Mini Review. Curr. Pharm. Des. 2016, 22, 1350-1360. [CrossRef]

8. Alfei, S.; Turrini, F.; Catena, S.; Zunin, P.; Grilli, M.; Pittaluga, A.; Boggia, R. Ellagic Acid a multi-target bioactive compound for drug discovery in CNS? A narrative review. Eur. J. Med. Chem. 2019, 183, 111724. [CrossRef]

9. Boggia, R.; Turrini, F.; Roggeri, A.; Olivero, G.; Cisani, F.; Bonfiglio, T.; Summa, M.; Grilli, M.; Caviglioli, G.; Alfei, S.; et al. Neuroinflammation in Aged Brain: Impact of the Oral Administration of Ellagic Acid Microdispersion. Int. J. Mol. Sci. 2020, 21, 3631. [CrossRef] [PubMed]

10. Magangana, T.P.; Makunga, N.P.; Fawole, O.A.; Opara, U.L. Processing Factors Affecting the Phytochemical and Nutritional Properties of Pomegranate (Punica granatum L.) Peel Waste: A Review. Molecules 2020, 25, 4690. [CrossRef] 
11. Turrini, F.; Boggia, R.; Donno, D.; Parodi, B.; Beccaro, G.L.; Baldassari, S.; Signorello, M.G.; Catena, S.; Alfei, S.; Zunin, P. From pomegranate marcs to a potential bioactive ingredient: A recycling proposal for pomegranate-squeezed marcs. Europ. Food Res. Technol. 2020, 246, 273-285. [CrossRef]

12. Turrini, F.; Zunin, P.; Catena, S.; Villa, C.; Alfei, S.; Boggia, R. Traditional or hydro-diffusion and gravity microwave coupled with ultrasound as green technologies for the valorization of pomegranate external peels. Food Bioprod. Process. 2019, $117,30-37$. [CrossRef]

13. Kim, S.A.; Go, A.; Jo, S.H.; Park, S.J.; Jeon, Y.U.; Kim, J.E.; Lee, H.K.; Park, C.H.; Lee, C.O.; Park, S.G.; et al. A novel cereblon modulator for targeted protein degradation. Eur. J. Med. Chem. 2019, 15, 65-74. [CrossRef]

14. Ríos, J.L.; Giner, R.M.; Marín, M.; Recio, M.C. A Pharmacological Update of Ellagic Acid. Planta Med. 2018, 84, 1068-1093. [CrossRef] [PubMed]

15. Saeed, M.; Naveed, M.; BiBi, J.; Kamboh, A.A.; Arain, M.A.; Shah, Q.A.; Alagawany, M.; El-Hack, M.E.A.; Abdel-Latif, M.A.; Yatoo, M.I.; et al. The Promising Pharmacological Effects and Therapeutic/Medicinal Applications of Punica granatum L. (Pomegranate) as a Functional Food in Humans and Animals. Recent Pat. Inflamm. Allergy Drug Discov. 2018, 12, 24-38. [CrossRef]

16. De Oliveira, M.R. The Effects of Ellagic Acid upon Brain Cells: A Mechanistic View and Future Directions. Neurochem. Res. 2016, 41, 1219-1228. [CrossRef]

17. Girish, C.; Raj, V.; Arya, J.; Balakrishnan, S. Evidence for the involvement of the monoaminergic system, but not the opioid system in the antidepressant-like activity of ellagic acid in mice. Eur. J. Pharmacol. 2012, 682, 118-125. [CrossRef]

18. Bhargava, U.C.; Westfall, B.A. The mechanism of blood pressure depression by ellagic acid. Proc. Soc. Exp. Biol. Med. 1969, 132, 754-756. [CrossRef] [PubMed]

19. Trendelenburg, A.U.; Philipp, M.; Meyer, A.; Klebroff, W.; Hein, L.; Starke, K. All three alpha2-adrenoceptor types serve as autoreceptors in postganglionic sympathetic neurons. Naunyn Schmiedebergs Arch. Pharmacol. 2003, 368, 504-512. [CrossRef]

20. Langer, S.Z. Presynaptic autoreceptors regulating transmitter release. Neurochem. Int. 2008, 52, 26-30. [CrossRef]

21. Schramm, N.L.; McDonald, M.P.; Limbird, L.E. The $\alpha 2$ A-adrenergic receptor plays a protective role in mouse behavioral models of depression and anxiety. J. Neurosci. 2001, 21, 4875-4882. [CrossRef]

22. Pittaluga, A.; Raiteri, L.; Longordo, F.; Luccini, E.; Barbiero, V.S.; Racagni, G.; Popoli, M.; Raiteri, M. Antidepressant treatments and function of glutamate ionotropic receptors mediating amine release in hippocampus. Neuropharmacology 2007, 53, 27-36. [CrossRef]

23. Vizi, E.S.; Kiss, J.P.; Lendvai, B. Nonsynaptic Communication in the Central Nervous System. Neurochem. Int. 2004, 45, 443-451. [CrossRef] [PubMed]

24. Jiang, J.L.; El Mansari, P.; Blier, M. Triple reuptake inhibition of serotonin, norepinephrine, and dopamine increases the tonic activation of $\alpha 2$-adrenoceptors in the rat hippocampus and dopamine levels in the nucleus accumbens. Prog. Neuropsychopharmacol. Biol. Psychiatry 2020, 103, 109987. [CrossRef] [PubMed]

25. Giorgi, F.S.; Biagioni, F.; Galgani, A.; Pavese, N.; Lazzeri, G.; Fornai, F. Locus Coeruleus Modulates Neuroinflammation in Parkinsonism and Dementia. Int. J. Mol. Sci. 2020, 21, 8630. [CrossRef]

26. Harrison, J.K.; Pearson, W.R.; Lynch, K.R. Molecular characterization of alpha 1- and alpha 2-adrenoceptors. Trends Pharmacol. Sci. 1991, 12, 62-67. [CrossRef]

27. Trendelenburg, A.U.; Klebroff, W.; Hein, L.; Starke, K. A study of presynaptic $\alpha 2$-autoreceptors in $\alpha 2 A / D-, \alpha 2 B-$ and $\alpha 2 C-$ adrenoceptor-deficient mice. Naunyn-Schmiedeberg's Arch. Pharmacol. 2001, 364, 117-130. [CrossRef]

28. Bonfiglio, T.; Olivero, G.; Vergassola, M.; Di Cesare Mannelli, L.; Pacini, A.; Iannuzzi, F.; Summa, M.; Bertorelli, R.; Feligioni, M.; Ghelardini, C.; et al. Environmental training is beneficial to clinical symptoms and cortical presynaptic defects in mice suffering from experimental autoimmune encephalomyelitis. Neuropharmacology 2019, 145, 75-86. [CrossRef]

29. Selmeczy, Z.; Vizi, E.S.; Csóka, B.; Pacher, P.; Haskó, G. Role of Nonsynaptic Communication in Regulating the Immune Response. Neurochem. Int. 2008, 52, 52-59. [CrossRef]

30. O'Sullivan, J.B.; Ryan, K.M.; Curtin, N.M.; Harkin, A.; Connor, T.J. Noradrenaline reuptake inhibitors limit neuroinflammation in rat cortex following a systemic inflammatory challenge: Implications for depression and neurodegeneration. Int. J. Neuropsychopharmacol. 2009, 12, 687-699. [CrossRef]

31. O'Sullivan, J.B.; Ryan, K.M.; Harkin, A.; Connor, T.J. Noradrenaline reuptake inhibitors inhibit expression of chemokines IP-10 and RANTES and cell adhesion molecules VCAM-1 and ICAM-1 in the CNS following a systemic inflammatory challenge. J. Neuroimmunol. 2010, 220, 34-42. [CrossRef]

32. Feinstein, D.L.; Heneka, M.T.; Gavrilyuk, V.; Dello Russo, C.; Weinberg, G.; Galea, E. Noradrenergic regulation of inflammatory gene expression in brain. Neurochem. Int. 2002, 41, 357-365. [CrossRef]

33. Szelényi, J.; Vizi, E.S. The catecholamine cytokine balance: Interaction between the brain and the immune system. Ann. N. Y. Acad. Sci. 2007, 1113, 311-324. [CrossRef]

34. Schrödinger Release 2018-1: Maestro; Schrödinger LLC: New York, NY, USA, 2018.

35. Schneider, J.; Korshunova, K.; Musiani, F.; Alfonso-Prieto, M.; Giorgetti, A.; Carloni, P. Predicting ligand binding poses for low-resolution membrane protein models: Perspectives from multiscale simulations. Biochem. Biophys. Res. Comm. 2018, 498, 366-374. [CrossRef] [PubMed]

36. Qu, L.; Zhou, Q.T.; Xu, Y.; Guo, Y.; Chen, X.Y.; Yao, D.; Han, G.W.; Liu, Z.-J.; Stevens, R.C.; Zhong, G.S.; et al. Structural basis of the diversity of adrenergic receptors. Cell Rep. 2019, 29, 2929-2935. [CrossRef] [PubMed] 
37. Chen, X.Y.; Wu, D.; Wu, L.J.; Han, G.W.; Guo, Y.; Zhong, G.S. Crystal structure of human alpha2C adrenergic G protein-coupled receptor. Released Protein Data Bank 2019. [CrossRef]

38. Schrödinger Release 2018-1: Protein Preparation Wizard; Schrödinger LLC: New York, NY, USA, 2018.

39. Schrödinger Release 2018-1: Epik; Schrödinger LLC: New York, NY, USA, 2018.

40. Jorgensen, W.L.; Maxwell, D.S.; Tirado-Rives, J. Development and testing of the OPLS all-atom force field on conformational energetics and properties of organic liquids. J. Am. Chem. Soc. 1996, 118, 11225-11236. [CrossRef]

41. Sastry, G.M.; Adzhigirey, M.; Day, T.; Annabhimoju, R.; Sherman, W. Protein and ligand preparation: Parameters, protocols, and influence on virtual screening enrichments. J. Comput.-Aided Mol. Des. 2013, 27, 221-234. [CrossRef]

42. Schrödinger Release 2018-1: LigPrep; Schrödinger LLC: New York, NY, USA, 2018.

43. Schrödinger Release 2018-1: Glide; Schrödinger LLC: New York, NY, USA, 2018.

44. Schrödinger Release 2018-1: Desmond Molecular Dynamics System; D.E. Shaw Research: New York, NY, USA, 2018.

45. Lomize, M.A.; Pogozheva, I.D.; Joo, H.; Mosberg, H.I.; Lomize, A.L. OPM database and PPM web server: Resources for positioning of proteins in membranes. Nucleic Acids Res. 2012, 40, D370-D376. [CrossRef]

46. Bowers, K.J.; Chow, D.E.; Xu, H.; Dror, R.O.; Eastwood, M.P.; Gregersen, B.A.; Klepeis, J.L.; Kolossvary, I.; Moraes, M.A.; Sacerdoti, F.D.; et al. Scalable Algorithms for Molecular Dynamics Simulations on Commodity Clusters. In Proceedings of the SC ‘06: Proceedings of the 2006 ACM/IEEE Conference on Supercomputing 2006, Tampa, FL, USA, 11-17 November 2006 ; p. 43. [CrossRef]

47. Chen, X.; Xu, Y.; Qu, L.; Wu, L.; Han, G.W.; Guo, Y.; Wu, Y.; Zhou, Q.; Sun, Q.; Chu, C.; et al. Molecular Mechanism for Ligand Recognition and Subtype Selectivity of $\alpha 2$ C Adrenergic Receptor. Cell Rep. 2019, 29, 2936-2943.e4. [CrossRef]

48. McMullan, M.; Kelly, B.; Mihigo, H.B.; Keogh, A.P.; Rodriguez, F.; Brocos-Mosquera, I.; García-Bea, A.; Miranda-Azpiazu, P.; Callado, L.F.; Rozas, I. Di-aryl guanidinium derivatives: Towards improved $\alpha 2$-Adrenergic affinity and antagonist activity. Europ. J. Med. Chem. 2021, 209, 112947. [CrossRef]

49. Hou, T.J.; Wang, J.M.; Li, Y.Y.; Wang, W. Assessing the performance of the MM/PBSA and MM/GBSA methods. 1. The accuracy of binding free energy calculations based on molecular dynamics simulations. J. Chem. Inf. Model. 2011, 51, 69-82. [CrossRef]

50. Kopitz, H.; Cashman, D.A.; Pfeiffer-Marek, S.; Gohlke, H. Influence of the solvent representation on vibrational entropy calculations: Generalized Born versus distance-dependent dielectric model. J. Comput. Chem. 2012, 12, 1004-1013. [CrossRef]

51. Genheden, S.; Ryde, U. The MM/PBSA and MM/GBSA methods to estimate ligand-binding affinities. Expert Opin. Drug Discov. 2015, 10, 449-461. [CrossRef]

52. Olivero, G.; Cisani, F.; Marimpietri, D.; Di Paolo, D.; Gagliani, M.C.; Podestà, M.; Cortese, K.; Pittaluga, A. The DepolarizationEvoked, Ca2+-Dependent Release of Exosomes from Mouse Cortical Nerve Endings: New Insights into Synaptic Transmission. Front. Pharmacol. 2021, 22, 670158. [CrossRef]

53. Olivero, G.; Bonfiglio, T.; Vergassola, M.; Usai, C.; Riozzi, B.; Battaglia, G.; Nicoletti, F.; Pittaluga, A. Immuno-pharmacological characterization of group II metabotropic glutamate receptors controlling glutamate exocytosis in mouse cortex and spinal cord. Br. J. Pharmacol. 2017, 174, 4785-4796. [CrossRef] [PubMed]

54. Raiteri, M.; Angelini, F.; Levi, G. A Simple Apparatus for Studying the Release of Neurotransmitters from Synaptosomes. Eur. J. Pharmacol. 1974, 25, 411-414. [CrossRef]

55. Di Prisco, S.; Merega, E.; Bonfiglio, T.; Olivero, G.; Cervetto, C.; Grilli, M.; Usai, C.; Marchi, M.; Pittaluga, A. Presynaptic, release-regulating mGlu2 -preferring and mGlu3 -preferring autoreceptors in CNS: Pharmacological profiles and functional roles in demyelinating disease. Br. J. Pharmacol. 2016, 173, 1465-1477. [CrossRef]

56. Raiteri, L.; Raiteri, M. Synaptosomes still viable after 25 years of superfusion. Neurochem. Res. 2000, 25, 1265-1274. [CrossRef] [PubMed]

57. Olivero, G.; Vergassola, M.; Cisani, F.; Usai, C.; Pittaluga, A. Immuno-Pharmacological Characterization of Presynaptic GluN3AContaining NMDA Autoreceptors: Relevance to Anti-NMDA Receptor Autoimmune Diseases. Mol. Neurobiol. 2019, 56, 6142-6155. [CrossRef]

58. Qu, L.; Zhou, Q.T.; Wu, D.; Zhao, S.W. Crystal structures of the alpha2A adrenergic receptor in complex with an antagonist RSC. Released Protein Data Bank 2019. [CrossRef]

59. Hou, T.J.; Wang, J.M.; Li, Y.Y.; Wang, W. Assessing the performance of the molecular mechanics/Poisson Boltzmann surface area and molecular mechanics/generalized Born surface area methods. II. The accuracy of ranking poses generated from docking. $J$. Comp. Chem. 2011, 32, 866-877. [CrossRef]

60. Kollman, P.A.; Massova, I.; Reyes, C.; Kuhn, B.; Huo, S.; Chong, L.; Lee, M.; Lee, T.; Duan, Y.; Wang, W.; et al. Calculating structures and free energies of complex molecules: Combining molecular mechanics and continuum models. Acc. Chem. Res. 2000, 33, 889-897. [CrossRef]

61. Wang, E.; Sun, H.; Wang, J.; Wang, Z.; Liu, H.; Zhang, J.Z.H.; Hou, T. End-Point Binding Free Energy Calculation with MM/PBSA and MM/GBSA: Strategies and Applications in Drug Design. Chem. Rev. 2019, 119, 9478-9508. [CrossRef] [PubMed]

62. Pittaluga, A. Acute Functional Adaptations in Isolated Presynaptic Terminals Unveil Synaptosomal Learning and Memory. Int. J. Mol. Sci. 2019, 20, 3641. [CrossRef] [PubMed] 
63. Raiteri, M.; Bonanno, G.; Maura, G.; Pende, M.; Andrioli, G.C.; Ruelle, A. Subclassification of release-regulating alpha 2autoreceptors in human brain cortex. Br. J. Pharmacol. 1992, 107, 1146-1151. [CrossRef] [PubMed]

64. Maura, G.; Pittaluga, A.; Ricchetti, A.; Raiteri, M. Noradrenaline uptake inhibitors do not reduce the presynaptic action of clonidine on 3H-noradrenaline release in superfused synaptosomes. Naunyn Schmiedebergs Arch. Pharmacol. 1984, 327, 86-89. [CrossRef] 